Article

\title{
The Inhibition of Aluminum Corrosion in Sulfuric Acid by Poly(1-vinyl-3-alkyl-imidazolium Hexafluorophosphate)
}

\author{
Paulina Arellanes-Lozada ${ }^{1}$, Octavio Olivares-Xometl ${ }^{2, *}$, Diego Guzmán-Lucero ${ }^{3}$, \\ Natalya V. Likhanova ${ }^{3}$, Marco A. Domínguez-Aguilar ${ }^{3}$, Irina V. Lijanova ${ }^{4}$ and \\ Elsa Arce-Estrada ${ }^{1}$
}

1 Instituto Politécnico Nacional, ESIQIE, Departamento de Metalurgia y Materiales, Av. Instituto Politécnico Nacional S/N, Col. Lindavista, México D.F. 07300, Mexico; E-Mails: arellanessss@gmail.com (P.A.-L.); earsa@ipn.mx (E.A.-E.)

2 Facultad de Ingeniería Química, Benemérita Universidad Autónoma de Puebla, Av. San Claudio, Ciudad Universitaria. Col. San Manuel, Puebla, Puebla 72570, Mexico

3 Instituto Mexicano del Petróleo, Programa de Investigación y Posgrado, Eje Central Lázaro Cárdenas No. 152, Col. San Bartolo Atepehuacán, México D.F. 07730, Mexico; E-Mails: djguzman@imp.mx (D.G.-L.); nvictoro@imp.mx (N.V.L.); madoming@imp.mx (M.A.D.-A.)

4 Instituto Politécnico Nacional, CIITEC, Cerrada Cecati S/N, Colonia Santa Catarina, Azcapotzalco, México D.F. 02250, Mexico; E-Mail: ivictorovnal@ipn.mx

* Author to whom correspondence should be addressed; E-Mail: octavio.olivares@correo.buap.mx or oxoctavio@yahoo.com.mx; Tel.: +52-559-175-8382.

Received: 8 May 2014; in revised form: 23 July 2014 / Accepted: 29 July 2014 /

Published: 7 August 2014

\begin{abstract}
Compounds of poly(ionic liquid)s (PILs), derived from imidazole with different alkylic chain lengths located in the third position of the imidazolium ring (poly(1-vinyl-3-dodecyl-imidazolium) $\left(\mathrm{PImC}_{12}\right)$, poly(1-vinyl-3-octylimidazolium) $\left(\mathrm{PImC}_{8}\right)$ and poly(1-vinyl-3-butylimidazolium) ( $\mathrm{PImC}_{4}$ ) hexafluorophosphate) were synthesized. These compounds were tested as corrosion inhibitors on aluminum alloy AA6061 in diluted sulfuric acid (0.1-1 $\left.\mathrm{M} \mathrm{H}_{2} \mathrm{SO}_{4}\right)$ by weight loss tests, polarization resistance measurements and inductively coupled plasma optical emission spectroscopy. Langmuir's isotherms suggested film formation on bare alloy while standard free energy indicated inhibition by a physisorption process. However, compound efficiencies as inhibitors ranked low $\left(\mathrm{PImC}_{12}>\mathrm{PImC}_{8}>\mathrm{PImC}_{4}\right)$ to reach $61 \%$ for $\mathrm{PImC}_{12}$ in highly diluted acidic solution. Apparently, the high mobility of sulfates favored their adsorption in comparison to PILs. The surface film displayed general corrosion, and pitting occurred as a consequence of
\end{abstract}


PILs' partial inhibition along with a continuous dissolution of defective patchy film on formation. A slight improvement in efficiency was displayed by compounds having high molecular weight and a long alkyl chain, as a consequence of steric hindrance and PIL interactions.

Keywords: alloys; surfaces; corrosion test; electrochemical techniques; adsorption

\section{Introduction}

Aluminum and its alloys find a wide variety of technological applications owing to the balanced combination of physical, mechanical and chemical properties, such as electrical and thermal conductivities, low density, high ductility, stability for surface treatments, good corrosion resistance, easiness of recycling and functional advantages of extruded and cast semi-products [1-3]. The addition of elements, such as copper, lithium, manganese, magnesium, silicon and zinc, allows aluminum to achieve a long range of bulk properties; likewise, minor additions provide an improvement in specific properties [4].

Aluminum generally exhibits passive behavior in aqueous solution due to the formation of a strong and compact adherent passive oxide film on the surface, which affects corrosion susceptibility. The adhesive passivating surface oxide film is amphoteric, and consequently, the metal is readily dissolved when exposed to aggressive acidic and alkaline solutions. In fact, the corrosion of metallic materials in acidic solution causes considerable costs $[5,6]$. In near-neutral solutions, the solubility of oxides will be much lower than in acidic solutions, and the extent of dissolution will tend to be smaller $[7,8]$.

The presence of aggressive ions (chlorides, fluorides) attacks the oxide film locally, and certain elements ( $\mathrm{Ga}, \mathrm{Tl}, \mathrm{In}, \mathrm{Sn}, \mathrm{Pb}, \mathrm{Fe}$ ) are incorporated into it, which may have a deleterious effect. Most commercial alloys contain several types of intermetallic phases, where aluminum corrosion occurred essentially as a micro-galvanic process between these secondary phases and the matrix alloy [9]. Sulfuric acid solutions are widely used for aluminum anodizing operations. Additionally, aluminum and its alloys are designated for industrial applications to manage a large variety of acid and alkaline solutions, but once dissolved, corrosion of the naturally-formed film can only be controlled by efficient inhibitors.

The use of chemicals as corrosion inhibitors (CIs) is one of the most popular and efficient methods to protect metals; this is a convenient and relatively inexpensive method to achieve this goal [10-13]. Organic compounds are commonly used as CIs in industry, such as those having $\pi$ electrons in structure and containing nitrogen, sulfur, phosphorus and oxygen atoms, through which they are adsorbed on the metal surface [14-19]. The adsorption is influenced by the electronic structure of the inhibiting molecules [20] and also by steric factors, aromaticity, electron density at the donor atoms and the presence of functional groups [21-23]. The use of polymers as CIs has attracted considerable attention due to their inherent stability and cost effectiveness [24-28]. Several families of homopolymers have been widely studied: polyacrylamide, polyvinyl pyrrolidone, polyacrylic acid and polyethyleneimine, It is known that polymers are strongly adsorbed on the surface, though giving lower toxicity than their analogues; hence, it is expected that polymers will be better corrosion inhibitors than 
the corresponding monomers [29,30]. Polymers may provide some advantages in comparison to other organic molecules: They provide a large single chain that displaces water molecules from metallic surface and makes inhibition more favorable. The presence of multiple bonding sites on the metallic surface makes polymer desorption a slow process [31]. Polymers form complexes with metal ions, and these complexes occupy a larger surface area, thereby blanketing the surface and protecting metal from the corrosive agents contained in solution [32].

In the present work, the effect of three poly(ionic liquid)s (PILs) (poly(1-vinyl-3dodecylimidazolium hexafluorophosphate), poly(1-vinyl-3-octylimidazolium hexafluorophosphate) and poly(1-vinyl-3-butylimidazolium hexafluorophosphate)) were tested as CIs in a concentration range within 10 to $100 \mathrm{mg} \cdot \mathrm{L}^{-1}(\mathrm{ppm})$ in aqueous sulfuric acid to prevent the corrosion of aluminum alloy AA6061. Weight loss tests, potentiodynamic polarization and surface analysis were used to support the proposed mechanism of inhibition. As not many polymers are considered as good corrosion inhibitors for non-ferrous metals and its alloys since surface adsorption is not always a straightforward process, it was decided to synthesize polymers based on ILs, as they possess a polymeric structure with surfactant components having positive and negative charges along with a hydrophobic chain

\section{Experimental Section}

\subsection{Synthesis and Characterization of PILs}

PILs were synthesized and characterized by ${ }^{1} \mathrm{H}$ and ${ }^{13} \mathrm{C}$ NMR and IR spectroscopies. Melting points were measured in a Fisher Scientific apparatus equipped with a $300{ }^{\circ} \mathrm{C}$ thermometer. FT-IR spectra were registered on a Nicolet FT-IR 5DX FT spectrophotometer as $\mathrm{KBr}$ discs. ${ }^{1} \mathrm{H}$ NMR (300 MHz) and ${ }^{13} \mathrm{C}$ NMR (75.4 MHz) spectra were obtained in a JEOL Eclipse-300 equipment using TMS as the internal standard. DMSO-d6 was used as solvent for $\mathrm{PImC}_{8}$ and $\mathrm{PImC}_{4}$, and $\mathrm{CDCl}_{3}$ for $\mathrm{PImC}_{12}$, in each case, dissolution was performed at room temperature. The gel permeation chromatography system was performed in a Waters 2410 refractive index detector with a 3 PL gel $10-\mu$ mixed-B columns to determine molecular weights. The GPC was calibrated with a polystyrene standard with tetrahydrofuran as the eluent.

The monomers of 1-vinyl-3-alkylimidazolium hexafluorophosphate were obtained according to the reported procedure [33], while the polymerization of 1-vinyl-3-alkylimidazolium hexafluorophosphates was carried out by free radical polymerization in solution using 2,2'-azo-bis(isobutyronitrile) as described elsewhere [34] to obtain white solid products in a 97\% yield. Table 1 shows the common chemical name and abbreviation for the compounds used in the present study. The polymerization was

proven by the disappearance of the peaks corresponding to the vinyl group in the ${ }^{1} \mathrm{H}$ NMR at 5.44, 5.96 and $7.26 \mathrm{ppm},{ }^{13} \mathrm{C} \mathrm{NMR}$ at 108.6 and $119.1 \mathrm{ppm}$ [19] and the appearance of new peaks corresponding to the polyvinyl group at around 3.24 and $2.2 \mathrm{ppm}$ in ${ }^{1} \mathrm{H}$ NMR (Table 2). 
Table 1. The poly(ionic liquid)s (PILs) tested as corrosion inhibitors.

\begin{tabular}{|c|c|c|c|c|c|}
\hline Abbreviation & Name & Structure & MW (g/mol) & DP & IR, $\mathrm{cm}^{-1}$ \\
\hline $\mathrm{PImC}_{12}$ & $\begin{array}{c}\text { Poly(1-vinyl-3- } \\
\text { dodecylimidazolium } \\
\text { hexafluorophosphate) }\end{array}$ & $\overline{\mathrm{PF}_{6}}$ & 60,500 & 148 & $\begin{array}{c}3,168,2,934,2,879 \\
1,553,1,475,837 \\
738,555\end{array}$ \\
\hline $\mathrm{PImC}_{8}$ & $\begin{array}{c}\text { Poly(1-vinyl-3- } \\
\text { octylimidazolium } \\
\text { hexafluorophosphate) }\end{array}$ & $\mathrm{PF}_{6}^{-}$ & 51,400 & 145 & $\begin{array}{c}3,168,2,931,2,859, \\
1,554,1,469,1,164, \\
835,736,557\end{array}$ \\
\hline $\mathrm{PImC}_{4}$ & $\begin{array}{c}\text { Poly(1-vinyl-3- } \\
\text { butylimidazolium } \\
\text { hexafluorophosphate) }\end{array}$ & 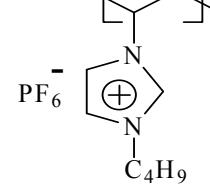 & 32,300 & 108 & $\begin{array}{c}3,166,2,969,2,881, \\
1,552,1,471,1,162, \\
836,738,557\end{array}$ \\
\hline
\end{tabular}

Table 2. NMR characterization of synthesized PILs.

\begin{tabular}{|c|c|c|c|c|c|c|c|}
\hline \multirow[b]{2}{*}{ IL } & \multicolumn{4}{|c|}{${ }^{1} \mathrm{H}$ NMR, ppm } & \multicolumn{3}{|c|}{${ }^{13} \mathrm{C}$ NMR, ppm } \\
\hline & $\begin{array}{l}\text { Alkylic } \\
\text { chain }\end{array}$ & $\begin{array}{c}\text { Imidazolium } \\
\text { ring }\end{array}$ & $\begin{array}{c}\text { Polymeric } \\
\text { chain }\end{array}$ & $\mathrm{N}-\mathrm{CH}_{2}$ & $\begin{array}{l}\text { Alkylic } \\
\text { chain }\end{array}$ & $\begin{array}{c}\text { Imidazolium } \\
\text { ring }\end{array}$ & $\mathrm{N}-\mathrm{CH}_{2}$ \\
\hline $\mathrm{PImC}_{12}$ & $\begin{array}{c}0.89(\mathrm{~b}, 3 \mathrm{H}) \\
1.26(\mathrm{~b}, 18 \mathrm{H}) \\
1.72(\mathrm{~b}, 2 \mathrm{H})\end{array}$ & $\begin{array}{l}7.32(\mathrm{~b}, 2 \mathrm{H}) \\
8.35(\mathrm{~b}, 1 \mathrm{H})\end{array}$ & $\begin{array}{l}1.86(\mathrm{~b}, 2 \mathrm{H}) \\
2.95(\mathrm{~b}, 1 \mathrm{H})\end{array}$ & $\begin{array}{c}4.09 \mathrm{~b} \\
2 \mathrm{H}\end{array}$ & $\begin{array}{c}14.30,22.91, \\
26.51,29.17(2 \mathrm{C}), \\
29.60(2 \mathrm{C}), \\
29.90(3 \mathrm{C}), 32.16\end{array}$ & $\begin{array}{l}123.83 \\
129.42 \\
136.12\end{array}$ & 51.60 \\
\hline $\mathrm{PImC}_{8}$ & $\begin{array}{c}0.89(\mathrm{~b}, 3 \mathrm{H}) \\
1.29(\mathrm{~b}, 10 \mathrm{H}) \\
1.69(\mathrm{~b}, 2 \mathrm{H})\end{array}$ & $\begin{array}{l}7.89(b, 2 H) \\
8.62(b, 1 H)\end{array}$ & $\begin{array}{l}2.28(\mathrm{~b}, 2 \mathrm{H}) \\
3.24(\mathrm{t}, 1 \mathrm{H})\end{array}$ & $\begin{array}{c}3.94 \mathrm{~b} \\
2 \mathrm{H}\end{array}$ & $\begin{array}{c}13.57,21.78, \\
25.70,28.15, \\
28.41,28.89, \\
30.95\end{array}$ & $\begin{array}{l}123.83 \\
128.87 \\
136.12\end{array}$ & 49.52 \\
\hline $\mathrm{PImC}_{4}$ & $\begin{array}{l}0.96(\mathrm{~b}, 3 \mathrm{H}) \\
1.35(\mathrm{~b}, 2 \mathrm{H}) \\
1.70(\mathrm{~b}, 2 \mathrm{H})\end{array}$ & $\begin{array}{l}7.68(\mathrm{~b}, 1 \mathrm{H}) \\
7.89(\mathrm{~b}, 1 \mathrm{H}) \\
8.66(\mathrm{~b}, 1 \mathrm{H})\end{array}$ & $\begin{array}{l}2.27(\mathrm{~b}, 2 \mathrm{H}) \\
3.24(\mathrm{~b}, 1 \mathrm{H})\end{array}$ & $\begin{array}{c}3.97 \mathrm{~b}, \\
2 \mathrm{H}\end{array}$ & $\begin{array}{c}12.88,18.78 \\
30.63\end{array}$ & $\begin{array}{l}123.44 \\
129.12 \\
134.49\end{array}$ & 49.08 \\
\hline
\end{tabular}

\subsection{Materials Preparation}

The experiments were performed on alloy AA6061 samples, because it is widely used in different technological applications. Its chemical composition is as follows (wt\%): 0.4/0.8 Si, 0.7 Fe, 0.15/0.4 Cu, 0.15 Mn, 0.8/1.2 Mg, 0.04/0.35 Cr, 0.25 Zn, 0.15 Ti, balanced with Al. Specimens were abraded with wet $\mathrm{SiC}$ paper number 400-4,000, degreased in hexane and washed in an ultrasonic bath of acetone for 5 min to remove impurities. The contact area used in the polarization resistance tests was $0.196 \mathrm{~cm}^{2}$; in order to do so, cylindrical specimens of $1.0 \mathrm{~cm} \times 0.5 \mathrm{~cm}$ were mounted in epoxy resin to secure the contact area. 


\subsection{Test Solution}

The test solution was prepared by using sulfuric acid of standard grade and deionized water. Aqueous solutions of $\mathrm{H}_{2} \mathrm{SO}_{4}(0.1,0.3,0.7$ and $1.0 \mathrm{M})$ were used to test PILs as CIs for AA6061. The compounds were added to the acid solutions in concentrations of $10,30,75$ and $100 \mathrm{mg} \cdot \mathrm{L}^{-1}(\mathrm{ppm})$.

\subsection{Weight Loss Measurements}

The cylindrical specimens $(1.5 \mathrm{~cm} \times 0.5 \mathrm{~cm})$ for weight loss measurements were immersed in solutions of diluted sulfuric acid with and without PILs $\left(100 \mathrm{mg} \cdot \mathrm{L}^{-1}\right)$. Inductively coupled plasma mass spectrometer (ICP-OES) model Varian 730-ES was employed to determine the amount of aluminum ions in $\mathrm{H}_{2} \mathrm{SO}_{4}$ solutions by the EPA 6010C method [35], after the immersion of aluminum alloy in the test solution for 30 days.

\subsection{Electrochemical Test}

Electrochemical measurements were carried out in a standard three-electrode cell. The counter electrode was a cylindrical bar of graphite; the reference electrode consisted of a commercial saturated calomel electrode (SCE) with a Luggin capillary probe, and the working electrode made of aluminum alloy AA6061 was embedded into a cylindrical bar made of Teflon. Tests were performed in a naturally aerated solution kept at a temperature of $25 \pm 1{ }^{\circ} \mathrm{C}$. Electrochemical tests were performed in a potentiostat/galvanostat PGSTAT302N controlled by a PC through the general purpose electrochemical system (GPES). Before recording the polarization resistance measurements $\left(R_{\mathrm{p}}\right)$, the working electrode was immersed in the test solution until the steady-state open circuit potential $\left(E_{\mathrm{OCP}}\right)$ was reached ( $\sim 15 \mathrm{~min})$. Polarization scans were then performed at a rate scan of $0.166 \mathrm{mV} \mathrm{s}^{-1}$ in the potential range of $\pm 20 \mathrm{mV} v s$. $E_{\mathrm{OCP}}$.

\subsection{Surface Analysis}

AA6061 aluminum alloy coupons were exposed to $1.0 \mathrm{M} \mathrm{H}_{2} \mathrm{SO}_{4}$ in the absence and presence of PILs $\left(100 \mathrm{mg} \cdot \mathrm{L}^{-1}\right)$ from $3 \mathrm{~h}$ to 30 days at $25 \pm 1{ }^{\circ} \mathrm{C}$. The metallic surface condition was recorded by SEM (scanning electron microscope) model JEOL-JSM-6300. Results of semi-quantitative elemental composition on sample were obtained by an EDX (electron dispersive X-ray) analyzer module attached to the microscope.

\section{Results and Discussion}

\subsection{Weight Loss Tests}

The corrosion rate of aluminum alloy AA6061 in the diluted solutions of $\mathrm{H}_{2} \mathrm{SO}_{4}$ was determined through the ICP-OES technique in the presence and absence of PILs after sample immersion for 30 days. Remainder solutions rich in aluminum ions provided the concentration of metallic ions in $\mathrm{mg} \cdot \mathrm{L}^{-1}$ after applying an analytical procedure [35]. From these concentrations and initial solution volume, the amount of aluminum ions in grams was determined. These values were expressed as weight loss measurements $(\mathrm{W})$ to determine the corrosion rate by the following Equation [36]. 


$$
C_{R}=\frac{K W}{A T D}
$$

where $C_{R}$ is the corrosion rate (mm/year), $K$ is a constant $\left(8.76 \times 10^{4}\right), W$ is the weight loss $(\mathrm{g}), T$ is the time the sample was exposed to the corrosive environment (h), $A$ is the surface area of exposed metallic surface $\left(\mathrm{cm}^{2}\right)$ and $D$ is the metal density $\left(\mathrm{g} / \mathrm{cm}^{3}\right)$.

Figure 1 shows the results obtained from gravimetric tests aided by the ICP-OES technique. It is observed that $C_{\mathrm{R}}$ increased with the concentration of sulfuric acid in water, in which the $\mathrm{pH}$ was determined $(1.1,0.9,0.6$ and 0.5$)$ for the different sulfuric acid concentrations $(0.1,0.3,0.7$ and 1.0$)$ as a measure of fluid aggressiveness.

Figure 1. Corrosion rate of aluminum alloy AA6061 in acidic solutions at $25{ }^{\circ} \mathrm{C}$ measured by the ICP-OES method.

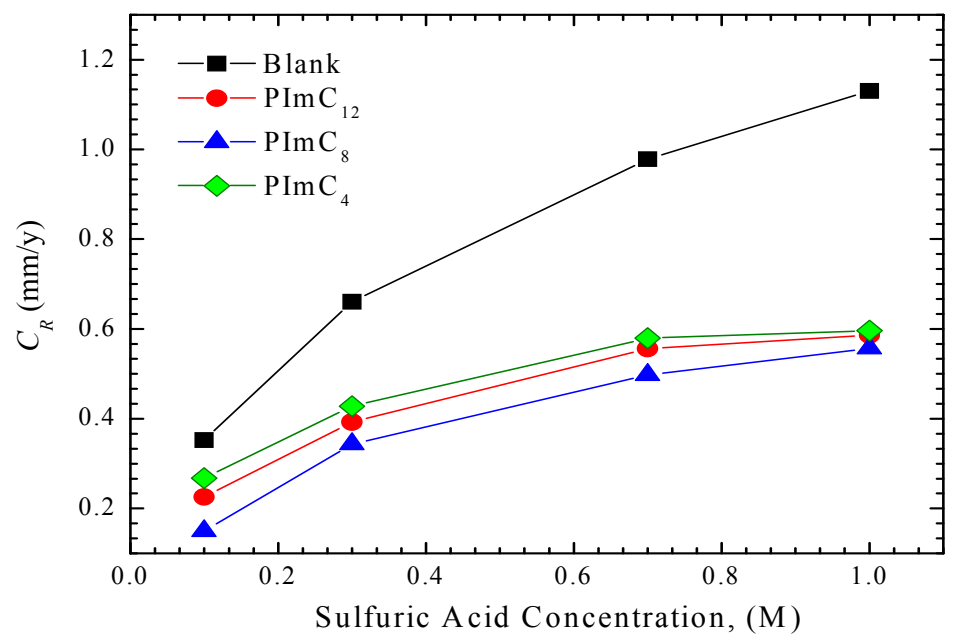

As higher concentrations of sulfates implied a higher concentrations of $\mathrm{Al}^{3+}$ ions in the aqueous environment, the reduction reactions on the cathode are catalyzed, which, in turn, accelerates oxidation reactions, thereby producing an increase in the corrosion rate. Figure 1 shows that the presence of PILs decreased the corrosion rate as inhibitor molecules were adsorbed on the aluminum surface to form a protective film that worked as a barrier that partially prevented ionic interchange; this way, the kinetics of electrochemical reactions are slowed and the corrosion rate on the metal surface is mitigated.

\subsection{Electrochemical Test}

Figure 2a,b show the graphs of current density $(i)$ as a function of overpotential $(\eta)$ for AA6061 in $0.1 \mathrm{M} \mathrm{H}_{2} \mathrm{SO}_{4}$ with and without the presence of $\mathrm{PImC}_{8}$ and $\mathrm{PImC}_{4}$, respectively. Similar curves to those displayed were obtained for the different inhibitor and acid concentrations. Slopes from figures show a decay as the PIL concentration is increased in the aqueous solution. In agreement with theory, $R_{\mathrm{p}}$ is inversely proportional to the potential current curve slope, which means that an increase in the concentration of CI produces an increase in the polarization resistance, and as a result, the corrosion rate is decreased. Similar curves to those displayed were obtained for the different inhibitor concentrations and acidic solutions. 
Figure 2. Potentiodynamic polarization curves of aluminum alloy AA6061 in $0.1 \mathrm{M} \mathrm{H}_{2} \mathrm{SO}_{4}$ with (a) $\mathrm{PImC}_{8}$ and (b) $\mathrm{PImC}_{4}$.
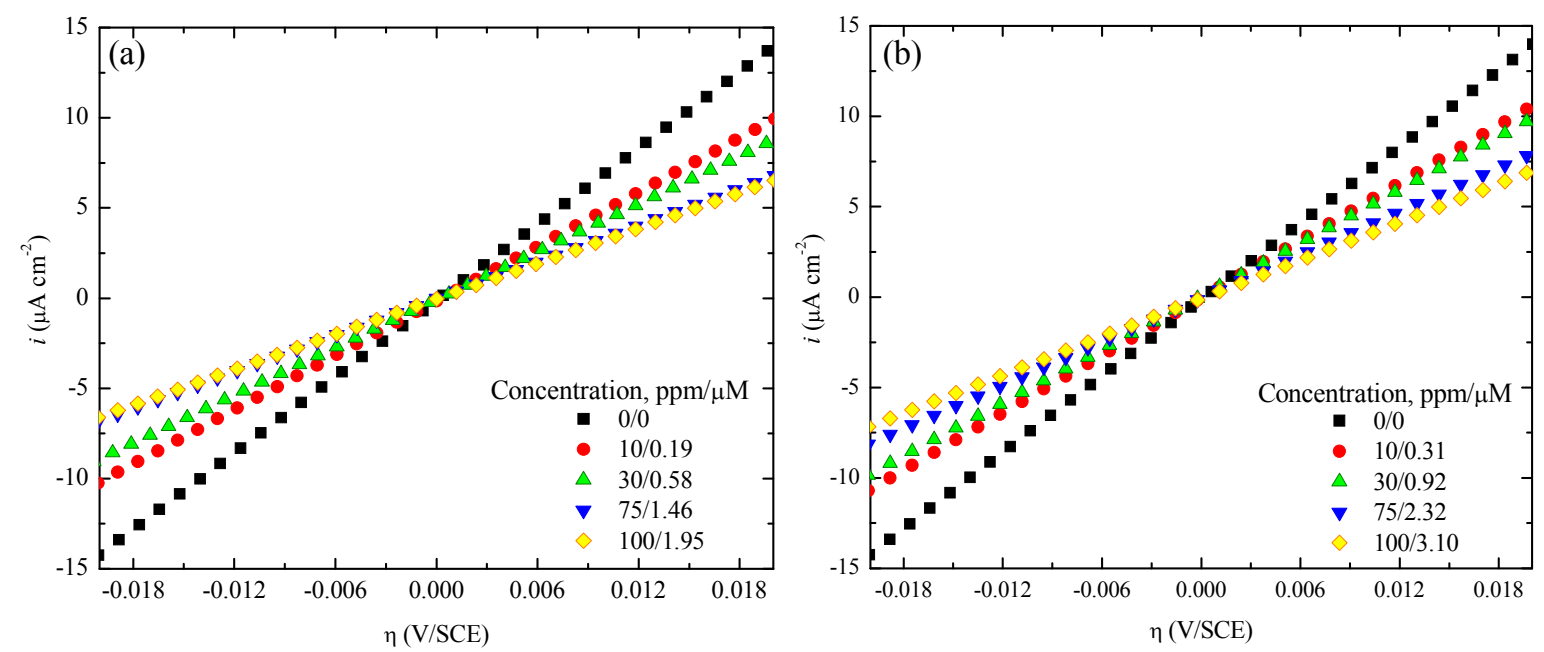

Table 3 summarizes the polarization resistances $\left(R_{\mathrm{p}}\right)$ for the tested concentrations in acid with and without CIs. The results in absence of PILs were 1423, 969, 940 and $924 \Omega \mathrm{cm}^{2}$ for the testing solution of $\mathrm{H}_{2} \mathrm{SO}_{4}$ at $0.1,0.3,0.7$ and $1.0 \mathrm{M}$, respectively. An increase in the concentration of $\mathrm{H}_{2} \mathrm{SO}_{4}$ resulted in a decrease of the $R_{\mathrm{p}}$ values, which implied an increase in metal dissolution; this observation was also supported by the ICP-OES tests that suggested an increase of the metallic ions in solution as shown in Figure $1 . R_{\mathrm{p}}$ tended to be proportional to PIL concentration; this behavior is derived from an increase in the resistance of the metal solution interface due to the film formed by the inhibitor and corrosion products that together contributed to isolating the metallic surface from ionic interchange, which led to surface passivation and contributed to mitigating the corrosion rate of alloy AA6061.

$R_{\mathrm{p}}$ values (Table 3) followed the order: $\mathrm{PImC}_{12}>\mathrm{PImC}_{8}>\mathrm{PImC}_{4}$. It is observed that the alkylic chain had an impact on the polarization resistance and, therefore, on corrosion inhibition, as reported elsewhere [37]; this way, $\mathrm{PImC}_{12}$ formed a denser film on the surface to enable greater protection when compared to the aliphatic chain lengths of the other PILs. Likewise, it is thought that the average molecular mass of polymer PImC $\operatorname{Im}_{12}(60,500 \mathrm{~g} / \mathrm{mol}, D P=148)$ and $\mathrm{PImC}_{8}(51,400 \mathrm{~g} / \mathrm{mol}, D P=145)$ may contribute to the increase of $R_{\mathrm{p}}$ due to the more efficient arrangement of polymeric film on the metallic surface. In contrast, $\mathrm{PImC}_{4}(32,300 \mathrm{~g} / \mathrm{mol}, D P=108)$ is less efficient as a result of both a smaller backbone and a smaller size of alkylic side chain than the others. Both factors contributed synergistically to decrease the metal-solution interaction with the consequent increase in $R_{\mathrm{p}}$ and the decrease in the corrosion rate.

Table 3 shows the change of $E_{\text {corr }}$ in the presence and absence of PIL compounds as a function of sulfuric acid molarity. These numbers display the maximum difference in absolute value between the corrosion potential of the blank material and any combination of PIL concentration and acid molarity; as a result, we have the largest differences, which are useful in determining the inhibitory nature. It is observed that the corrosion potentials in the anodic branches of $\mathrm{PImC}_{12}, \mathrm{PImC}_{8}$ and $\mathrm{PImC}_{4}$ are 17, 25 and $41 \mathrm{mV}$ ( $v s$. SCE); whereas for the cathodic branches, they are 25, 25 and $45 \mathrm{mV}$ ( $v s . \mathrm{SCE}$ ), respectively. As none of these values surpassed the reference change of $85 \mathrm{mV}$ in any direction, it is claimed that PILs can be classified as mixed type inhibitors [38]. 
Table 3. Electrochemical parameters derived from polarization resistance tests on aluminum alloy AA6061 at $25^{\circ} \mathrm{C}$. CI, corrosion inhibitor.

\begin{tabular}{|c|c|c|c|c|c|c|c|c|c|}
\hline \multirow[b]{2}{*}{ CI } & \multirow[b]{2}{*}{$\begin{array}{l}\text { Concentration } \\
(\mathbf{p p m} / \mu \mathrm{M})\end{array}$} & \multicolumn{2}{|c|}{$0.1 \mathrm{M} \mathrm{H}_{2} \mathrm{SO}_{4}$} & \multicolumn{2}{|c|}{$0.3 \mathrm{M} \mathrm{H}_{2} \mathrm{SO}_{4}$} & \multicolumn{2}{|c|}{$0.7 \mathrm{M} \mathrm{H}_{2} \mathrm{SO}_{4}$} & \multicolumn{2}{|c|}{$1.0 \mathrm{M} \mathrm{H}_{2} \mathrm{SO}_{4}$} \\
\hline & & $\begin{array}{c}\boldsymbol{R}_{\mathbf{p}} \\
\left(\mathrm{Ohm} \cdot \mathrm{cm}^{2}\right)\end{array}$ & $\begin{array}{c}-E_{\text {corr }} \\
(\mathrm{mV})\end{array}$ & $\begin{array}{c}\boldsymbol{R}_{\mathbf{p}} \\
\left(\Omega \cdot \mathrm{cm}^{2}\right)\end{array}$ & $\begin{array}{c}-E_{\text {corr }} \\
(\mathrm{mV})\end{array}$ & $\begin{array}{c}\boldsymbol{R}_{\mathbf{p}} \\
\left(\Omega \cdot \mathrm{cm}^{2}\right)\end{array}$ & $\begin{array}{l}-\boldsymbol{E}_{\text {corr }} \\
(\mathrm{mV})\end{array}$ & $\begin{array}{c}\boldsymbol{R}_{\mathbf{p}} \\
\left(\Omega \cdot \mathrm{cm}^{2}\right)\end{array}$ & $\begin{array}{l}-\boldsymbol{E}_{\text {corr }} \\
(\mathrm{mV})\end{array}$ \\
\hline \multirow{5}{*}{$\mathrm{PImC}_{12}$} & Blank materialAA6061 & 1,423 & 657 & 969 & 651 & 940 & 621 & 924 & 653 \\
\hline & $10 / 0.16$ & 2,270 & 658 & 1,340 & 647 & 1,288 & 639 & 970 & 636 \\
\hline & $30 / 0.49$ & 2,523 & 653 & 1,491 & 676 & 1,373 & 620 & 1,072 & 642 \\
\hline & $75 / 1.24$ & 3,334 & 650 & 1,952 & 660 & 1,543 & 644 & 1,203 & 659 \\
\hline & $100 / 1.65$ & 3,663 & 641 & 2,070 & 658 & 1,667 & 639 & 1,242 & 654 \\
\hline \multirow{4}{*}{$\mathrm{PImC}_{8}$} & $10 / 0.19$ & 1,982 & 670 & 1,313 & 646 & 1,245 & 643 & 930 & 652 \\
\hline & $30 / 0.58$ & 2,260 & 647 & 1,405 & 655 & 1,345 & 646 & 1,013 & 650 \\
\hline & $75 / 1.46$ & 2,942 & 646 & 1,843 & 642 & 1,469 & 641 & 1,131 & 655 \\
\hline & $100 / 1.95$ & 3,052 & 642 & 2,003 & 639 & 1,543 & 644 & 1,176 & 659 \\
\hline \multirow{4}{*}{$\mathrm{PImC}_{4}$} & $10 / 0.31$ & 1,889 & 657 & 1,283 & 669 & 1,240 & 666 & 929 & 618 \\
\hline & $30 / 0.92$ & 2,034 & 663 & 1,369 & 665 & 1,308 & 632 & 1,001 & 612 \\
\hline & $75 / 2.32$ & 2,495 & 646 & 1,679 & 665 & 1,434 & 643 & 1,074 & 623 \\
\hline & $100 / 3.10$ & 2,832 & 647 & 1,727 & 655 & 1,517 & 655 & 1,136 & 623 \\
\hline
\end{tabular}

The corrosion inhibitor efficiency $I_{\mathrm{E}}(\%)$ of PILs was determined by the $R_{\mathrm{p}}$ values:

$$
I_{\mathrm{E}}=\left(\frac{R_{\mathrm{p}}^{i}-R_{\mathrm{p}}^{0}}{R_{\mathrm{p}}^{i}}\right) \times 100
$$

where $R_{\mathrm{p}}{ }^{i}$ and $R_{\mathrm{p}}{ }^{0}$ are the corresponding measurements determined in the presence and absence of PILs. In Table 4, a summary of the $I_{\mathrm{E}}$ is provided for each PIL concentration as a function of the sulfuric acid molarity. The values suggested that PILs mitigated corrosion on the testing material AA6061. It is important to note that the top efficiency was obtained at $100 \mathrm{mg} \cdot \mathrm{L}^{-1}$ for every PIL under test, even though $\mathrm{PImC}_{12}$ with an alkylic chain composed of 12 carbon atoms displayed the highest $I_{\mathrm{E}}(\sim 61 \%)$.

A possible explanation of the relatively fair inhibitor performance may include the following: A film of aluminum oxide $\left(\mathrm{Al}_{2} \mathrm{O}_{3}\right)$ is spontaneously formed on the alloy; this film provides protection until it is partially dissolved in the acidic solution [39]. However, on inhibition treatment, the PIL formed another film on the alloy [40], which is partially compact and defective; a lack of compactness is derived from deficient chain stacking, which avoids forming a fully dense polymeric film on the substrate. Furthermore, the relatively high concentrations of sulfuric acid and low ones of the inhibitor in solution implied a large amount of sulfate ions and free protons; both chemical species compete with PILs macromolecules in occupying the active sites on the metallic surface. A chance to create defects at the interface metal-film due to hydrogen accumulation and sulfate ions' high mobility is likely, although in acid corrosion, the anodic reactions predominate, as metal is lost through the dissolution of sulfates and blistering is not generated. Additionally, the patchy nature of the protective film of the inhibitor allowed for local activity; these conditions contributed to secondary oxidation reactions, which prevented the surface from having complete coverage and a higher PIL efficiency. This process occurred and had a deleterious effect on the corrosion inhibitory efficiency despite the high molecular weight (backbone) and alkylic side chain) and long backbone of the PIL molecule. 
Table 4. Inhibition efficiency of PILs on aluminum alloy at $25^{\circ} \mathrm{C}$.

\begin{tabular}{cccccc}
\hline \multirow{2}{*}{$\mathbf{C I}$} & $\begin{array}{c}\text { Concentration } \\
(\mathbf{p p m} / \boldsymbol{\mu M})\end{array}$ & $\mathbf{0 . 1} \mathbf{M ~ H}_{\mathbf{2}} \mathbf{S O}_{\mathbf{4}}$ & $\mathbf{0 . 3} \mathbf{M ~ H}_{\mathbf{2}} \mathbf{S O}_{\mathbf{4}}$ & $\mathbf{0 . 7} \mathbf{M ~ H}_{\mathbf{2}} \mathbf{S O}_{\mathbf{4}}$ & $\mathbf{1 . 0} \mathbf{M ~ H}_{\mathbf{2}} \mathbf{S O}_{\mathbf{4}}$ \\
\hline \multirow{4}{*}{$\mathrm{PImC}_{12}$} & $10 / 0.16$ & 37 & 28 & 27 & 5 \\
& $30 / 0.49$ & 44 & 35 & 31 & 14 \\
& $75 / 1.24$ & 57 & 50 & 39 & 23 \\
& $100 / 1.65$ & 61 & 53 & 44 & 25 \\
\hline \multirow{4}{*}{$\mathrm{PImC}_{8}$} & $10 / 0.19$ & 28 & 26 & 24 & 1 \\
& $30 / 0.58$ & 37 & 31 & 30 & 9 \\
& $75 / 1.46$ & 52 & 47 & 36 & 18 \\
& $100 / 1.95$ & 53 & 52 & 39 & 21 \\
$\mathrm{PImC}_{4}$ & $10 / 0.31$ & 25 & 24 & 24 & 1 \\
& $30 / 0.92$ & 30 & 29 & 28 & 8 \\
& $75 / 2.32$ & 43 & 42 & 34 & 14 \\
\hline
\end{tabular}

In Table 4 is observed that PILs efficiency depends on their concentration in solution, and for each concentration, there is a particular time to reach their highest efficiency. Likewise it was observed that $\mathrm{PImC}_{12}$ reached the highest efficiency despite the similar structure to another PIL, but it has the largest aliphatic side chain; these parameters suggest that efficiency depends on the molecular structure of inhibitor, inhibitor concentration, aggressiveness of testing environment and type of metallic material. However, these parameters are integrated in the nature of the adsorption process, as the efficiency of organic molecules depends on their capability of being adsorbed on the metal surface. It is worth noting that adsorption on the corroded surfaces never reaches the real equilibrium, but it tends to a steady state; when corrosion is sufficiently small, adsorption tends to be in quasi-equilibrium [41], but in contrast, when corrosion is sufficiently high, adsorption is difficult to reach, which is the case of sulfates over PIL molecules. This way, every PIL required a certain time and concentration for a specific structure to reach its peak efficiency.

The open circuit potential as a function of time was determined in the testing solutions in absence of electric polarization to have an insight of PIL adsorption on the alloy AA 6061 under naturally aerated conditions. Figure 3 displays the corresponding measurements of $E_{\mathrm{OCP}}$ ( $v s$. SCE) as a function of immersion time at $1.0 \mathrm{M} \mathrm{H}_{2} \mathrm{SO}_{4}$ in the presence of $\mathrm{PImC}_{12}$. In the absence of a corrosion inhibitor, for the first minutes, the curve potential time displayed a displacement towards positive values due to the rapid formation of the passive film of aluminum oxide as a result of its highly active nature. For longer times, in the range of one hour, the curve was displaced to negative values of potential; this tendency was ascribed to the dissolution of the oxide passive film as a result of the adsorption of sulfate ions $\left(\mathrm{SO}_{4}{ }^{2}\right)$ and the formation of subsequent soluble complex $\mathrm{Al}_{2}\left(\mathrm{SO}_{4}\right)_{3}\left(\mathrm{H}_{2} \mathrm{O}\right)_{n}$. The cathodic reactions involved in hydrogen evolution on the aluminum surface contributed with the $\mathrm{SO}_{4}{ }^{2-}$ ions to the damage of the passive film. After two hours of potential monitoring, the $E_{\mathrm{OCP}}$ tended to equilibrium at about $-685 \mathrm{mV}$ ( $v s$. SCE), which was ascribed to the corrosion potential $E_{\text {corr }}$ [42]. 
Figure 3. Time dependence of open circuit potential of aluminum alloy AA6061 in $1.0 \mathrm{M}$ $\mathrm{H}_{2} \mathrm{SO}_{4}$ acquired in the presence of $\mathrm{PImC}_{12}$.

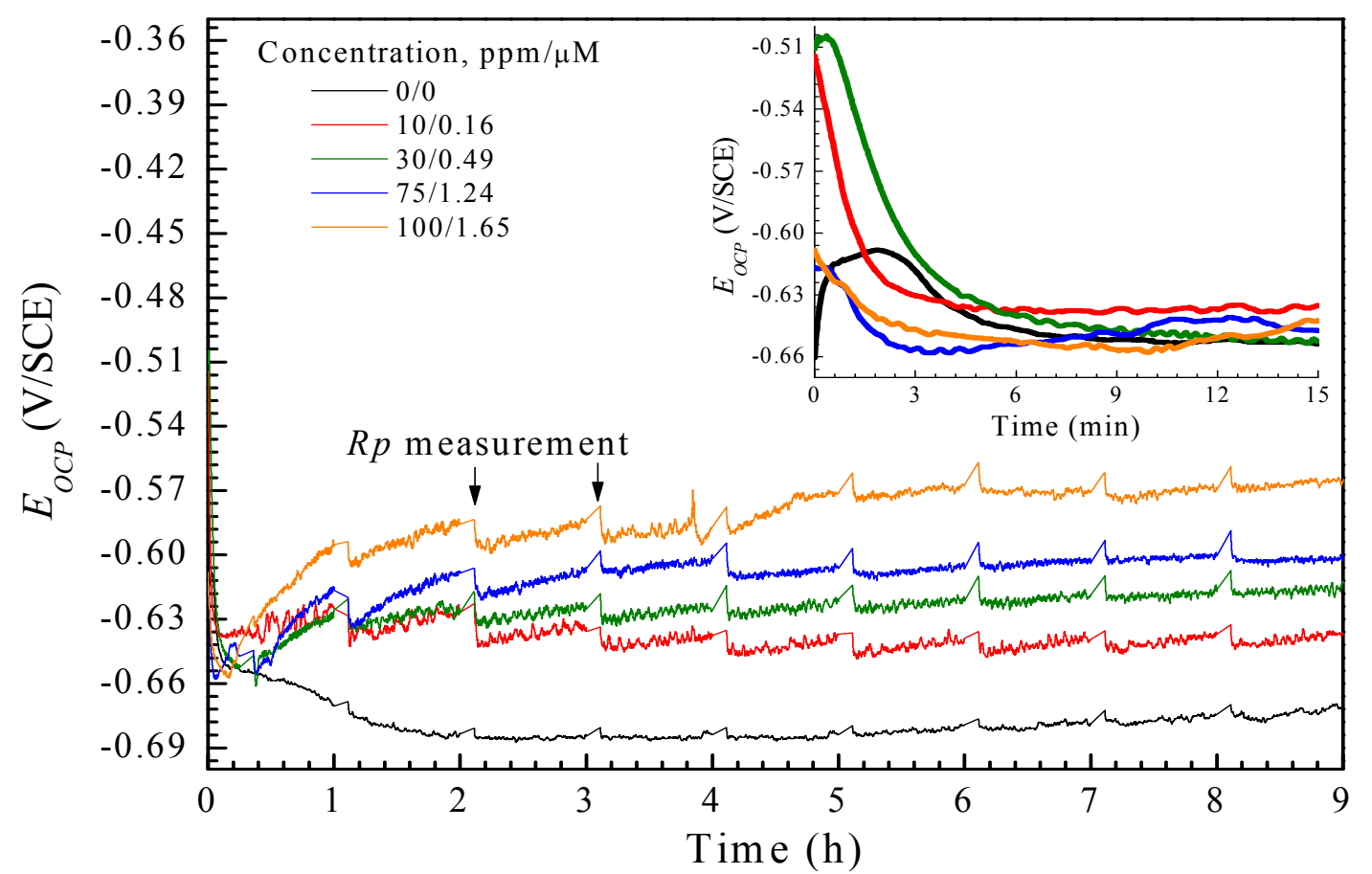

The addition of $\mathrm{PImC}_{12}$ to the acidic solution showed a drastic change in the behavior of the $E_{\mathrm{OCP}}$ in comparison to the solution in the absence of the inhibitor. At the beginning, a displacement to negative potential values was observed due to the dissolution of passive film, whereas at higher concentrations of $\mathrm{PImC}_{12}$, within a time period of 30 minutes, $E_{\mathrm{OCP}}$ showed an increase to positive values, now due to film formation with molecules of $\mathrm{H}_{2} \mathrm{O}, \mathrm{SO}_{4}{ }^{2-}$, aluminum oxides and $\mathrm{PImC}_{12}$, which contributed to corrosion protection [43]. In summary, the addition of $\mathrm{PImC}_{12}$ to the system moved $E_{\text {corr }}$ to positive potentials; a similar behavior was observed for $\mathrm{PImC}_{8}$ and $\mathrm{PImC}_{4}$. The anodic displacements of $E_{\text {corr }}$ for $\mathrm{PImC}_{12}, \mathrm{PImC}_{8}$ and $\mathrm{PImC}_{4}$ were about $100 \mathrm{mV}, 80 \mathrm{mV}$ and $70 \mathrm{mV}$ vs. SCE, respectively, which suggested that the presence of CIs affected the aggressive environment and mainly the anodic reaction within the testing times.

Polarization scans were performed following the potential measurements to determine the film formation stability. The curve profile in Figure 3 displays the decay of $E_{\mathrm{OCP}}$ every hour, and Table 5 provides the values of $I_{\mathrm{E}}$ obtained from $R_{\mathrm{p}}$ of the alloy with and without CIs as immersion time dependent. When immersion time was increased, the PILs efficiency decreased, apparently because film formation tended to be less compact as a result of macromolecular desorption, which provided an increase of the active sites occupied by $\mathrm{H}_{2}, \mathrm{SO}_{4}{ }^{2-}, \mathrm{OH}^{-}$and $\mathrm{H}_{3} \mathrm{O}^{+}$. The $R_{\mathrm{p}}$ values as a function of testing time and concentration followed the same order: $\mathrm{PImC}_{12}>\mathrm{PImC}_{8}>\mathrm{PImC}_{4}$, as indicated by previous results. 
Table 5. Inhibition efficiency of PILs on aluminum alloy AA6061 as a function of immersion times at $25^{\circ} \mathrm{C}$.

\begin{tabular}{cccccc}
\hline \multirow{2}{*}{ CI } & \multirow{2}{*}{ Time (h) } & \multicolumn{5}{c}{$\boldsymbol{I}_{\mathbf{E}} \mathbf{( \% )}$} \\
\cline { 3 - 6 } & & $\mathbf{1 0} \mathbf{~ p p m}$ & $\mathbf{3 0} \mathbf{~ p p m}$ & $\mathbf{7 5} \mathbf{~ p p m}$ & $\mathbf{1 0 0} \mathbf{~ p p m}$ \\
\hline \multirow{4}{*}{$\mathrm{PImC}_{12}$} & 1 & 18 & 23 & 40 & 63 \\
& 3 & 24 & 30 & 37 & 66 \\
& 6 & 23 & 30 & 36 & 55 \\
& 9 & 21 & 29 & 38 & 53 \\
\hline \multirow{3}{*}{$\mathrm{PImC}_{8}$} & 1 & 15 & 20 & 38 & 59 \\
& 3 & 18 & 21 & 30 & 61 \\
& 6 & 20 & 26 & 29 & 47 \\
& 9 & 18 & 21 & 30 & 47 \\
\hline \multirow{3}{*}{$\mathrm{PImC}_{4}$} & 1 & 14 & 16 & 26 & 44 \\
& 3 & 12 & 19 & 27 & 39 \\
& 6 & 15 & 20 & 25 & 41 \\
& 9 & 10 & 15 & 30 & 41 \\
\hline
\end{tabular}

\subsection{Adsorption Isotherms}

The effect of inhibition on the corrosion of metallic materials is mainly ascribed to the molecular adsorption of the corrosion inhibitor on the metal surface. A metallic surface when in contact with an aqueous solution is saturated with water molecules, whereas in the presence of a corrosion inhibitor, these molecules displaced the adsorbed water. On water substitution by CI molecules, the latter block the active sites on the metallic surface where corrosion reactions occur.

Isotherms provide an idea of the adsorption and desorption processes and the interactions of metal-inhibitor molecules on the metallic surface. To understand the inhibition process of AA6061 in sulfuric acid, the experimental data were related to adsorption isotherms, which described the operative process between inhibitor-metal. Langmuir (Equation (3)), Temkin (Equation (4)) and Freundlich (Equation (5)) were considered to observe PILs tendency [44]:

$$
\begin{gathered}
K_{\text {ads }} C=\frac{\theta}{1-\theta} \\
K_{\text {ads }} C=\mathrm{e}^{f \theta} \\
K_{\text {ads }} C=\theta
\end{gathered}
$$

where $K_{\text {ads }}$ is the equilibrium constant of adsorption, $C$ is the inhibitor concentration, $f$ is the interaction constant and $\theta$ the fraction of the surface covered; the latter parameter has a direct relation with the inhibitor efficiency by means of the following equation [45].

$$
\theta=\frac{I_{\mathrm{E}}}{100}
$$

Figure 4a,b shows the fitting of experimental data based on Langmuir's adsorption model when testing A6061 in $0.1 \mathrm{M}$ and $0.7 \mathrm{M} \mathrm{H}_{2} \mathrm{SO}_{4}$, respectively. In Table 6, it is observed that the correlation 
coefficients were close to the unit, which corroborated that PILs are relatively easily adsorbed on the metal surface and follow the predicted model of the Langmuir isotherm.

Figure 4. Langmuir's isotherms for aluminum alloy AA6061 in (a) $0.1 \mathrm{M}$ and (b) $0.7 \mathrm{M}$ $\mathrm{H}_{2} \mathrm{SO}_{4}$ solutions with PILs as CIs.
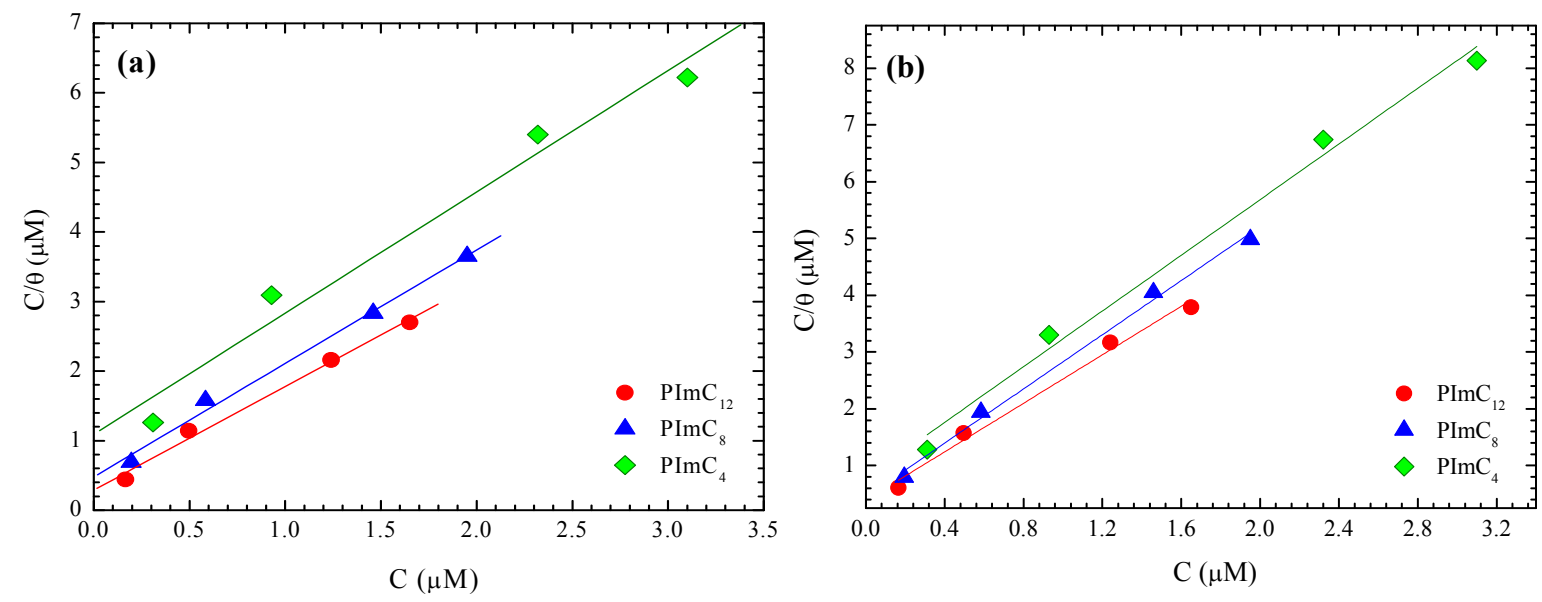

Table 6. Summary of fundamental adsorption constants of PILs of aluminum alloy AA 6061 at $25^{\circ} \mathrm{C}$.

\begin{tabular}{cccccc}
\hline $\mathbf{H}_{\mathbf{2}} \mathbf{S O}_{\mathbf{4}}$ Solution (M) & $\mathbf{C I}$ & $\boldsymbol{R}^{\mathbf{2}}$ & Slope & $\boldsymbol{K}_{\text {ads }}\left(\mathbf{m m o l}^{\mathbf{- 1}}\right)$ & $-\boldsymbol{\Delta G}_{\text {ads }}^{\mathbf{0}}\left(\mathbf{k J} \cdot \mathbf{m o l}^{-\mathbf{1}}\right)$ \\
\hline \multirow{3}{*}{0.1} & $\mathrm{PImC}_{12}$ & 0.98 & 1.49 & 3,431 & 30.1 \\
& $\mathrm{PImC}_{8}$ & 0.98 & 1.63 & 2,089 & 28.9 \\
& $\mathrm{PImC}_{4}$ & 0.95 & 1.74 & 917 & 26.9 \\
\hline \multirow{3}{*}{0.3} & $\mathrm{PImC}_{12}$ & 0.98 & 1.63 & 2,219 & 29.1 \\
& $\mathrm{PImC}_{8}$ & 0.96 & 1.65 & 1,550 & 28.2 \\
& $\mathrm{PImC}_{4}$ & 0.98 & 1.99 & 1,062 & 27.2 \\
\hline \multirow{3}{*}{0.7} & $\mathrm{PImC}_{12}$ & 0.98 & 2.14 & 2,567 & 29.4 \\
& $\mathrm{PImC}_{8}$ & 0.99 & 2.38 & 2,253 & 29.1 \\
& $\mathrm{PImC}_{4}$ & 0.98 & 2.45 & 1,276 & 27.7 \\
\hline \multirow{3}{*}{1.0} & $\mathrm{PImC}_{12}$ & 0.99 & 2.09 & 350 & 25.0 \\
& $\mathrm{PImC}_{8}$ & 0.97 & 1.73 & 179 & 22.8 \\
& $\mathrm{PImC}_{4}$ & 0.75 & 2.21 & 96 & 21.3 \\
\hline
\end{tabular}

The values of $K_{\text {ads }}$ obtained from the intersection of Langmuir's isotherms to the origin are reported in Table 6 for the presence of $\mathrm{PImC}_{12}$; the highest values of $K_{\text {ads }}$ were obtained for the different concentrations tested in diluted sulfuric acid. This indicated that the compounds of high molecular weights $\left(\mathrm{PImC}_{12}\right)$ and long side chains were more easily adsorbed on the alloy surface. It appeared that the alkyl side groups of each repeating unit of the polymeric CIs naturally created hydrophobic interactions among them, which decreased available water molecules in content to interact with other hydrophobic tails. This way, an alkyl side group of longer aliphatic chains present in the backbone can produce stronger hydrophobic interactions, which, in turn, decreased the amount of aggressive ions affecting the metallic surface [46]. Figure 5 provides an idea of PILs' interaction with both the metallic surface and the aggressive environment in an attempt to describe a likely mechanism of adsorption and 
later PIL inhibition of AA6061 in diluted sulfuric acid. The interaction among the hydrophobic parts of the PILs molecules could support the protective action. However, it is more likely that the main chains of the polymer form an obstacle, as the lateral alkylic chains were haphazardly placed along the main chains of the polymer, which may have a supportive action on inhibition, as they hinder the pass of water and aggressive ions, in agreement with their hydrophobic nature. The steric hindrance is more efficiently carried out when the alkyl side chain is composed of 12 carbons, as it can interact with the other lateral alkylic groups to slow molecular diffusion. The probability of these interactions among alkylic side chains consisting of eight and four carbons decreased markedly, so that water molecules can pass more easily. The main chain of the macromolecules can be placed one above the other as a result of the opposite ionic attractions that can evolve in different points of two or more adjacent macrochains to form the protective film.

Figure 5. Schematic representation of molecular adsorption and later PIL inhibition of aluminum alloy AA6061 in diluted sulfuric acid.

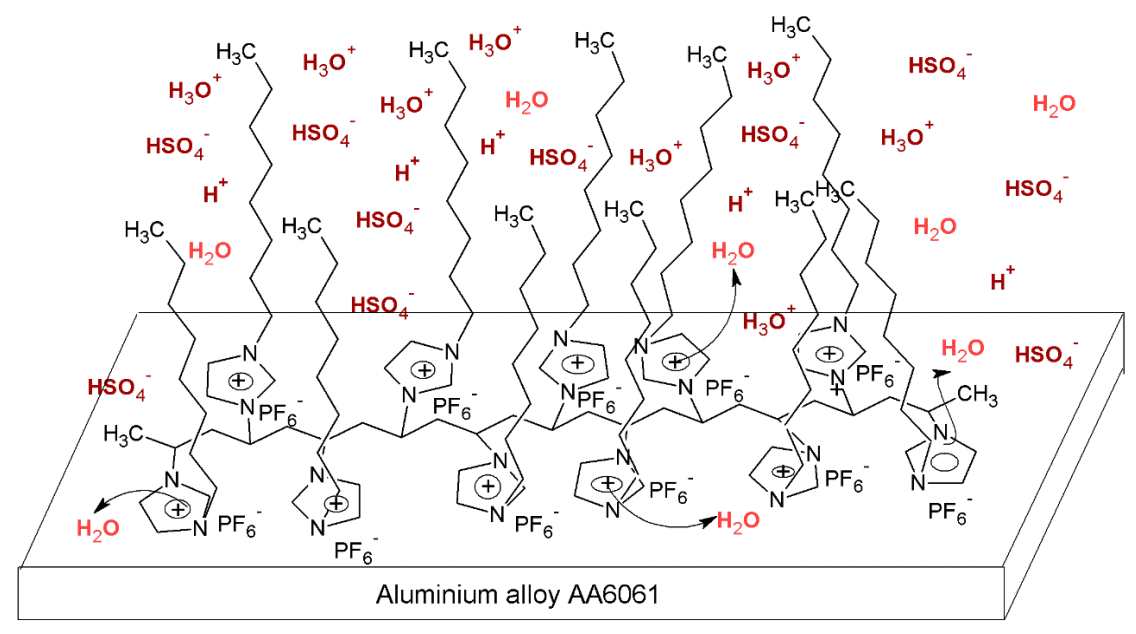

The values of $K_{\text {ads }}$ were used to determine the standard free energy of adsorption $\left(\Delta G_{\text {ads }}^{0}\right)$ as indicated in the following Equation:

$$
\Delta G_{\text {ads }}^{0}=-R T \ln \left(55.5 K_{\text {ads }}\right)
$$

where $R$ is the gas universal constant $\left(8.314 \mathrm{~J} \cdot \mathrm{mol}^{-1} \cdot \mathrm{K}^{-1}\right)$, T is the absolute temperature of the aggressive medium, $\left(K_{\text {ads }}\right)$ and 55.5 stands for the molar concentration of water $(\mathrm{M})$. The values of $\Delta G_{\text {ads }}^{0}$ are displayed in Table 6, which showed only negative ones, suggesting that the Cis' adsorption process occurred, that is to say, PILs formed an adsorbed film on the aluminum alloy surface. PILs in the aqueous media produced a negative change in the adsorption free energy as a result of water and ion displacement from the metallic surface. Negative values persisted even at $0.1 \mathrm{M} \mathrm{H}_{2} \mathrm{SO}_{4}$ as an indication that PILs adsorption is favored even when the number of sulfate aggressive ions and protons in solution tended to be lower.

When the values of $\Delta G_{\text {ads }}^{0}$ are equal to $-20 \mathrm{~kJ} \cdot \mathrm{mol}^{-1}$ or less negative, this thermodynamic parameter suggests an adsorption process determined by the electrostatic attraction forces between the ionic charges and the dipoles of the adsorbed chemical species and the electric charge of metal in the metal-solution interface, which indicates that a physisorption process has occurred [47]. On the other 
hand, the $\Delta G_{\text {ads }}^{0}$ derived in values of $-40 \mathrm{~kJ} \cdot \mathrm{mol}^{-1}$ or more negative ones suggested that a chemisorption process is under control, in which the CIs are capable of forming chemical bonds with the surface as electrons move into the metallic surface to form a coordinated type of bond with the metallic surface [48]. The values of $\Delta G_{\text {ads }}^{0}$ for these molecules were determined in the range of -30 to $-21 \mathrm{~kJ} \cdot \mathrm{mol}^{-1}$, which means that compounds were adsorbed on the metallic surface by a process of physical adsorption.

\subsection{Surface Analysis}

\subsubsection{Sample Surface after $3 \mathrm{~h}$ of Immersion}

Figure 6a shows the scanning electron micrograph of alloy AA6061 without etching, where a surface is observed with oriented and uniform lines produced by mechanical polishing; EDX analysis in Figure $6 \mathrm{~b}$ indicated that aluminum is the main constituent in the alloy. Figure 7a shows the surface appearance of the alloy after immersion in $1.0 \mathrm{M} \mathrm{H}_{2} \mathrm{SO}_{4}$ for three hours, where a heterogeneous surface with small pits of different form $(1,2)$ is displayed. In this case, the EDX spectrum described the characteristic signals of aluminum, in addition to other elements, such as oxygen and sulfur, which are common as corrosion products of aluminum in sulfuric acid when a complex of type $\mathrm{Al}_{2}\left(\mathrm{SO}_{4}\right)_{3}\left(\mathrm{H}_{2} \mathrm{O}\right)_{n}$ is formed [49].

Figure 6. (a) SEM and (b) EDX analysis of aluminum alloy AA6061 before exposure to the acidic medium.

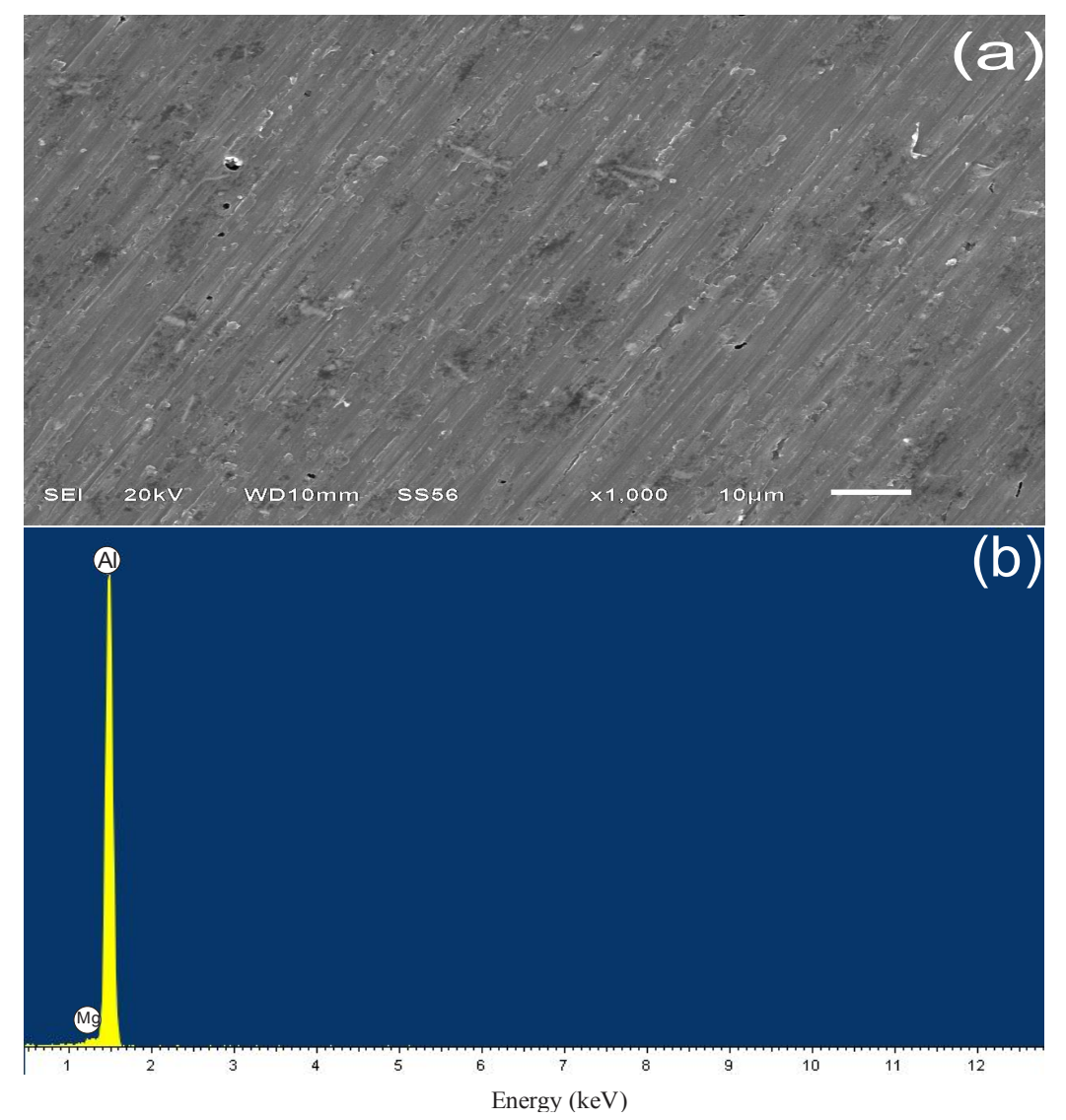


Figure 7. SEM (a) and EDX (b) analysis of aluminum alloy AA6061 after exposure for $3 \mathrm{~h}$ in $1.0 \mathrm{M} \mathrm{H}_{2} \mathrm{SO}_{4}$.

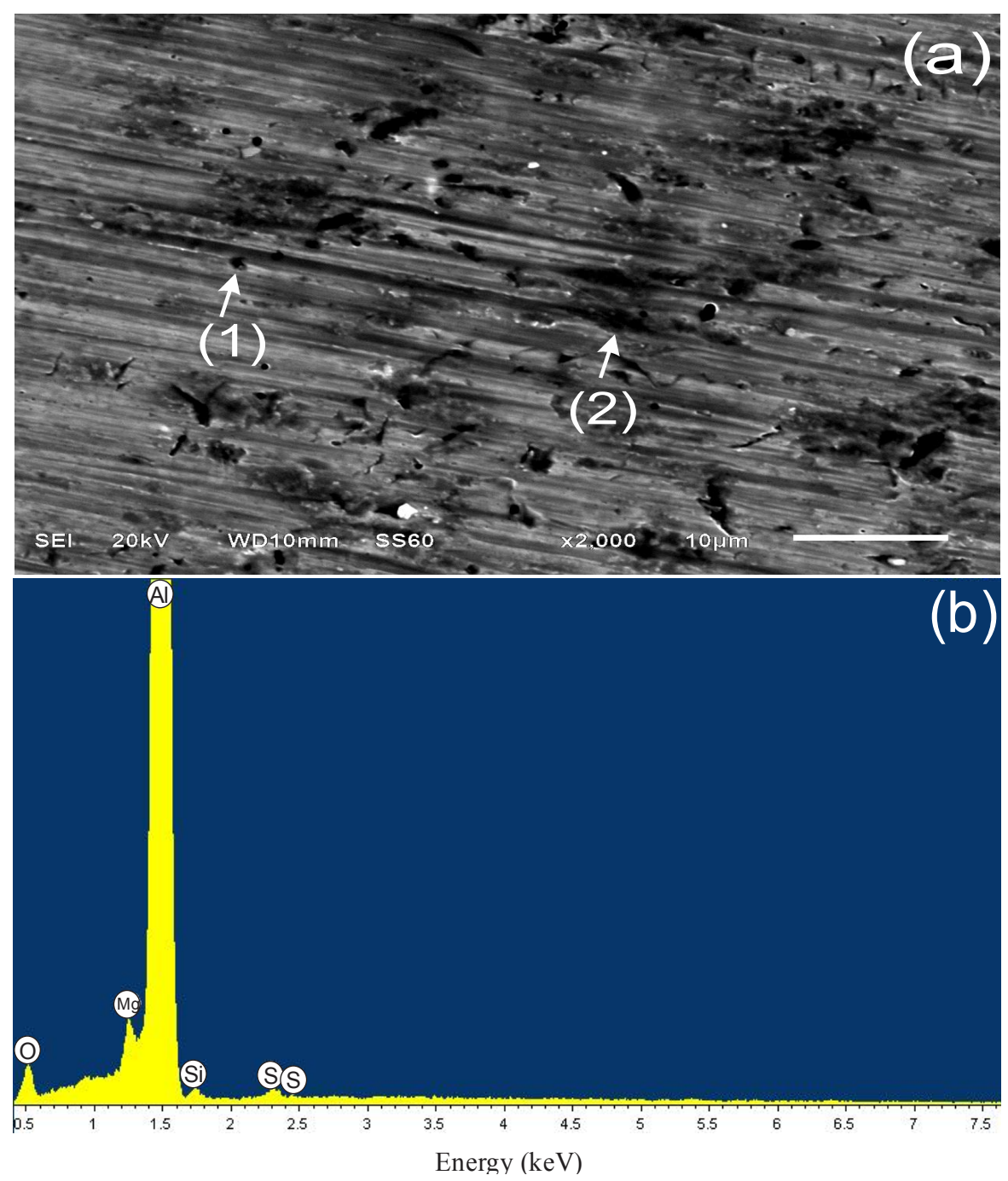

The micrograph in Figure 8a shows the alloy surface in the presence of $\mathrm{PImC}_{12}$. In comparison to the blank morphology, there are regions displaying general corrosion in addition to pits with an average lower density and individual diameters. EDX analysis in Figure $8 \mathrm{~b}$ corroborated the presence of oxygen in a lower concentration, and sulfur appeared in the spectrum, which suggested that PILs decreased the formation of the soluble complex $\mathrm{Al}_{2}\left(\mathrm{SO}_{4}\right)_{3}\left(\mathrm{H}_{2} \mathrm{O}\right)_{n}$ and, thereby, decreased the kinetics of the corrosion reactions. The carbon signal, which was absent in the blank material, was attributed to the presence of PILs molecules on the surface; the presence of $\mathrm{PImC}_{12}, \mathrm{PImC}_{8}$, and $\mathrm{PImC}_{4}$ qualitatively indicated a carbon content of $4.8 \%$ to roughly $32 \%$ in different regions of the alloy surface. Table 7 shows the percentages of the elements present on the analyzed surfaces with and without IC presence. 
Figure 8. (a) SEM and (b) EDX analysis of aluminum alloy AA6061 after exposure for three hours in $1.0 \mathrm{M} \mathrm{H}_{2} \mathrm{SO}_{4}$ with the addition of 100 ppm of $\mathrm{PImC}_{12}$.

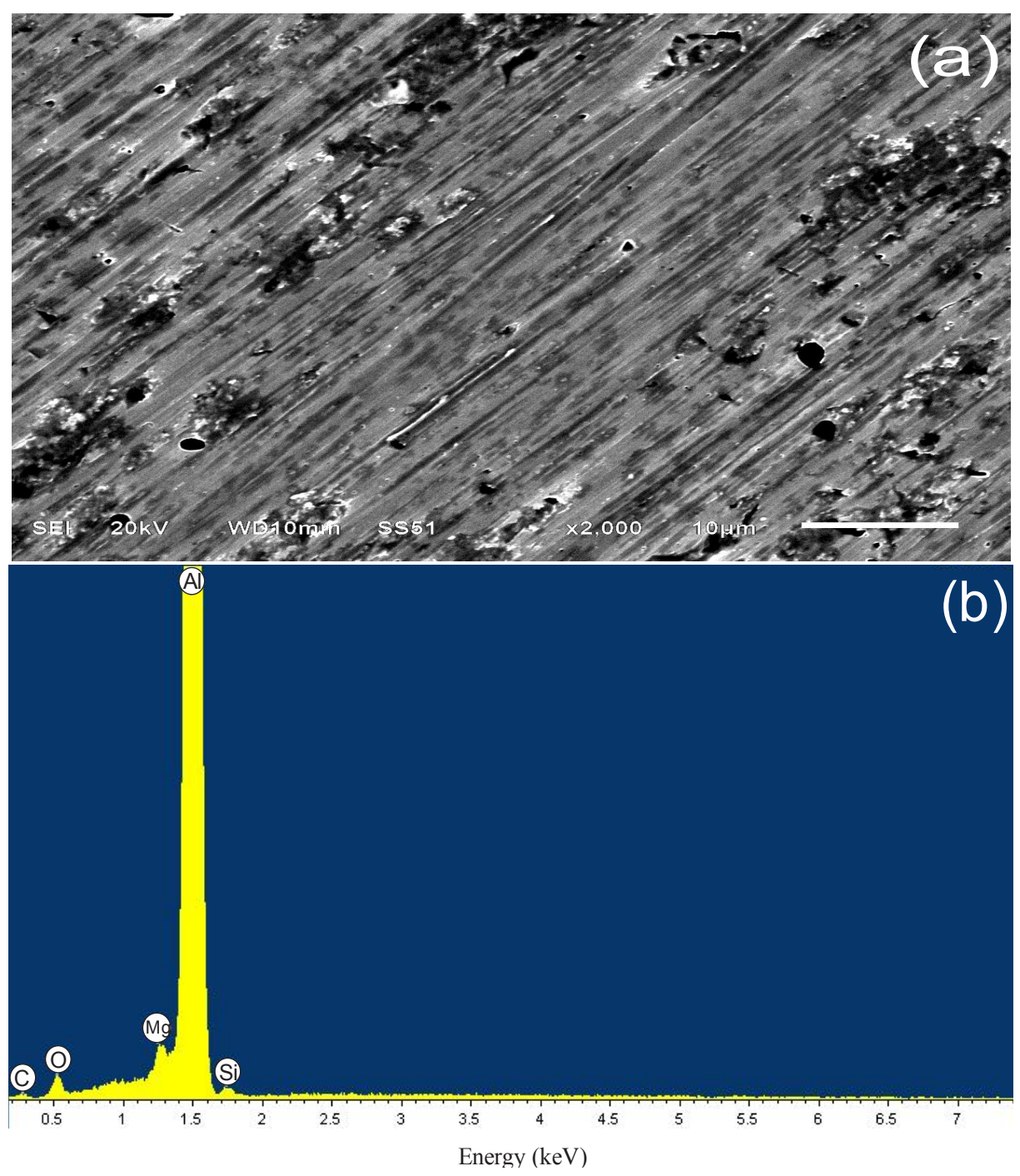

Table 7. Weight percent of the elements present in the AA6061 alloy after a 3-h exposure in $1.0 \mathrm{M} \mathrm{H}_{2} \mathrm{SO}_{4}$.

\begin{tabular}{cccccccc}
\hline \multirow{2}{*}{ Spectrum } & \multicolumn{7}{c}{ Weight \% } \\
\cline { 2 - 8 } & $\mathbf{C}$ & $\mathbf{O}$ & $\mathbf{M g}$ & $\mathbf{A l}$ & $\mathbf{S i}$ & $\mathbf{S}$ & Total \\
\hline Without attack & - & - & 1.02 & 98.98 & - & - & 100 \\
Blank & - & 6.17 & 0.9 & 91.83 & 0.64 & 0.46 & 100 \\
$\mathrm{PImC}_{12}$ & 8.28 & 5.01 & 0.76 & 85.3 & 0.66 & - & 100 \\
$\mathrm{PImC}_{8}$ & 4.83 & 2.77 & 0.78 & 91.12 & 0.51 & - & 100 \\
$\mathrm{PImC}_{4}$ & 9.42 & 3.52 & 0.74 & 85.67 & 0.65 & - & 100 \\
\hline
\end{tabular}

\subsubsection{Sample Surface after 30 Days of Immersion}

Figure 9a shows the micrograph of the AA6061 surface after an immersion time of 30 days in $1.0 \mathrm{M} \mathrm{H}_{2} \mathrm{SO}_{4}$ without CI. A rearrangement of porous corrosion products in islands is observed as a 
result of the limited growth. Porosity allows a continuous diffusion of aggressive ions and, as a result, the continuous corrosion of metal. On addition of $100 \mathrm{ppm}\left(1.65 \times 10^{-3} \mathrm{mM}\right)$ of $\mathrm{PImC}_{12}$ in acidified solution (Figure 9), the alloy surface displayed the following important changes: (1) the boundaries among the corrosion products are not distinguished; and (2) the number and diameter of holes decreased. The EDX analysis of the zone highlighted in yellow indicated the presence of carbon $(34.2 \mathrm{wt} \%)$ in a higher concentration when compared to the analysis referred to in Figure 8b, which suggests that the adsorption process is relatively continuous, probably because of the affinity that could exist between the complex $\mathrm{Al}_{2}\left(\mathrm{SO}_{4}{ }^{2-}\right)_{3}\left(\mathrm{H}_{2} \mathrm{O}\right)_{n}$ and the inhibitor. Additionally, the $\mathrm{CI}$ can also be present on the corrosion products, and since chemical interactions could not be necessarily on the active sites, the PILs' efficiency as inhibitors was adversely affected.

Figure 9. SEM of aluminum alloy AA6061 surface after exposure for 30 days in acidic solution (a) without PIL and (b) with $100 \mathrm{mg} \cdot \mathrm{L}^{-1}$ of $\mathrm{PImC}_{12}$.

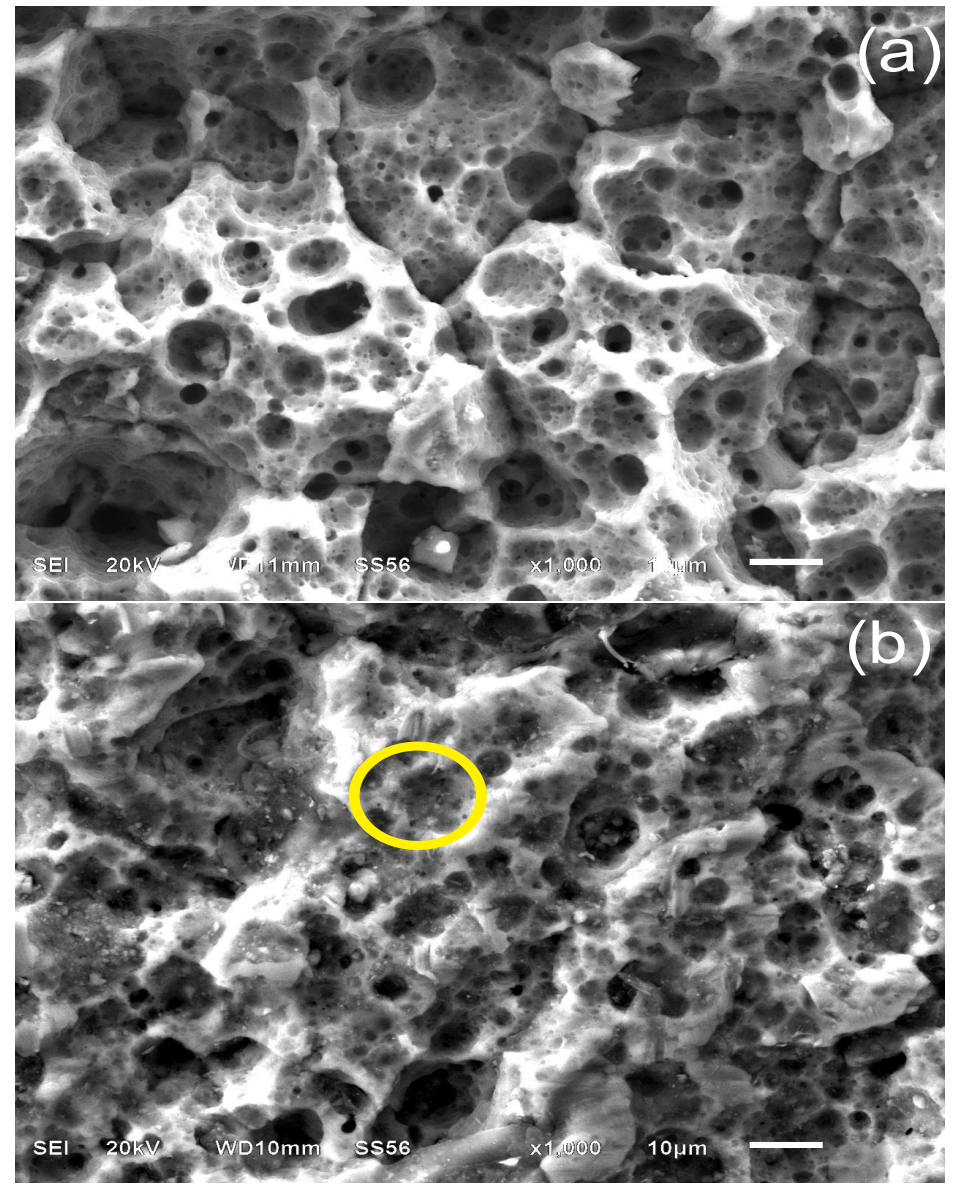

Figure 10 shows a cross-section micrograph of alloy AA6061 after testing for 30 days. Pitting is associated with (a) $\mathrm{Al}_{2}\left(\mathrm{SO}_{4}{ }^{2-}\right)_{3}\left(\mathrm{H}_{2} \mathrm{O}\right)_{n}$, as the surface revealed pits with a depth of approximately $50 \mu \mathrm{m}$. Figure $10 \mathrm{~b}$ corresponds to a micrograph with the addition of $\mathrm{PImC}_{12}$. In comparison to Figure 10a, pit type is mainly elliptic and depth decreased around $15 \mu \mathrm{m}$. The decrease in pit depth and their change in pit morphology indicated that PIL protected metal surface and, therefore, decreased this type of localized damage. 
Figure 10. SEM image of a cross-section of the aluminum alloy AA6061 surface after exposure for 30 days in the acidic solution (a) without PILs and (b) with $100 \mathrm{mg} \cdot \mathrm{L}^{-1}$ of $\mathrm{PImC}_{12}$.

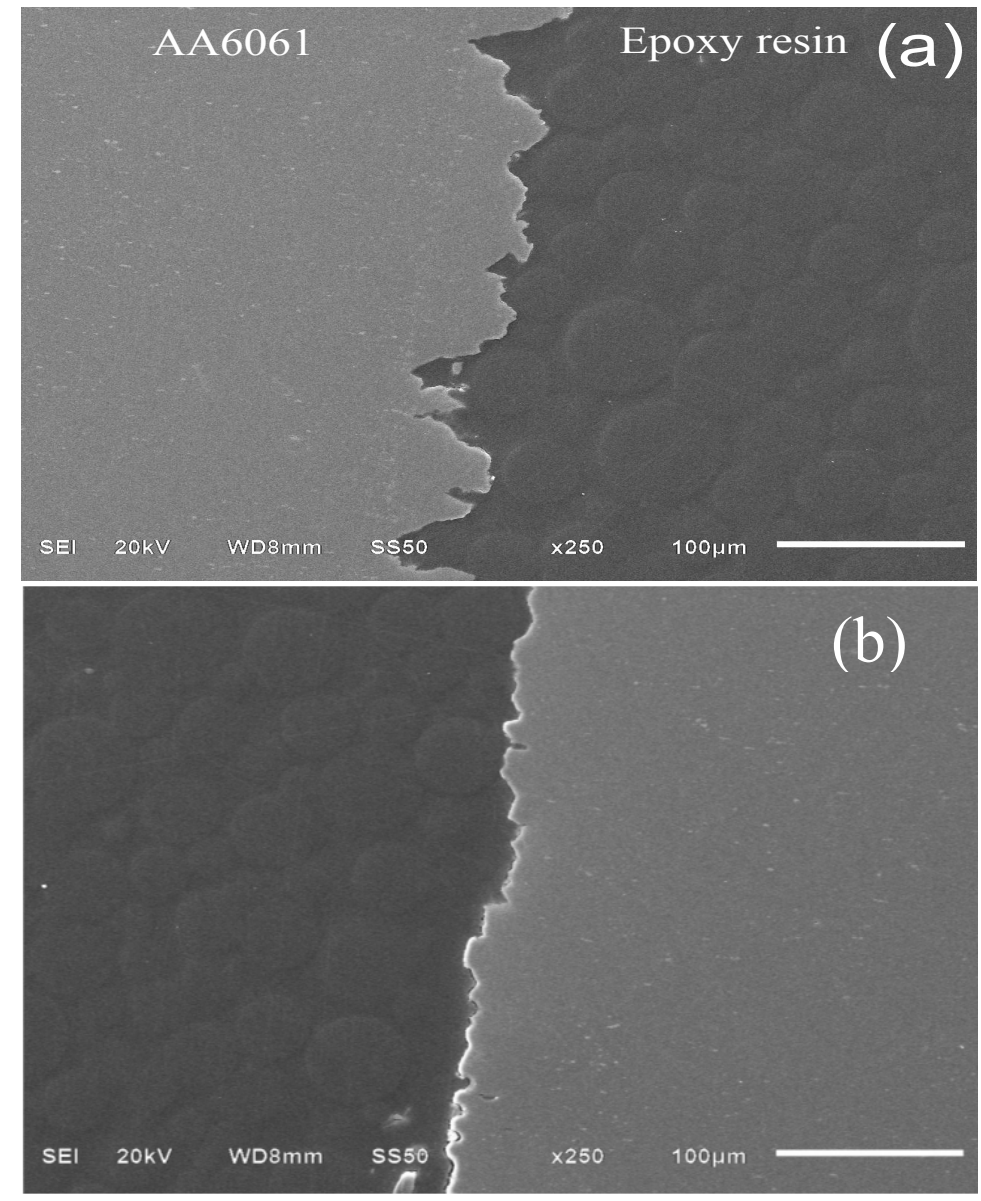

\subsection{Adsorption Mechanism}

The inhibitor efficiency of PILs against corrosion of alloy AA6061 in aqueous solution of $\mathrm{H}_{2} \mathrm{SO}_{4}$ is a result of molecular adsorption at the metal-solution interface. As a natural reaction of aluminum, it suddenly reacts in contact with oxygen and water to give aluminum oxide $\mathrm{Al}_{2} \mathrm{O}_{3}$. In addition, some elements that are part of alloy AA6061's composition formed oxide and hydroxides in an aqueous environment, and depending on their nature, corrosion resistance is worsened or improved. Several authors have postulated the mechanism of aluminum corrosion in diluted acid solutions in a similar fashion to that occurring on iron, though considering that the aluminum surface is free from oxides; in fact, the dissolution mechanism of aluminum corrosion in acid and alkaline environments is still under discussion [50-52].

\subsubsection{Anodic Reactions}

In Figure 11, corrosion and inhibition mechanisms are suggested to explain aluminum alloy behavior. In the anodic zones of alloy AA6061 in the absence of PILs, a protective oxide film is formed on the surface (Equation (8)), which can be destroyed under the action of the diluted sulfuric acid 
(Equation (9)) by the interaction of the hydrated film of aluminum oxide with bisulfate anions when $\mathrm{Al}_{2}\left(\mathrm{SO}_{4}\right)_{3}\left(\mathrm{H}_{2} \mathrm{O}\right)_{n}$, ads is formed. As this complex is soluble in the aqueous environment, it is then desorbed from the surface, leaving free active sites to be attacked again by the anions of $\mathrm{HSO}_{4}{ }^{-}$or $\mathrm{SO}_{4}{ }^{2-}$.

$$
\begin{gathered}
4 \mathrm{Al}+n \mathrm{H}_{2} \mathrm{O}+3 \mathrm{O}_{2} \rightarrow 2 \mathrm{Al}_{2} \mathrm{O}_{3}\left(\mathrm{H}_{2} \mathrm{O}\right)_{n} \\
\mathrm{Al}_{2} \mathrm{O}_{3}\left(\mathrm{H}_{2} \mathrm{O}\right)_{n}+3 \mathrm{HSO}_{4}^{-}+3 \mathrm{H}^{+} \leftrightarrow \mathrm{Al}_{2}\left[\left(\mathrm{SO}_{4}\right)_{3}\left(\mathrm{H}_{2} \mathrm{O}\right)_{n}\right]_{\mathrm{ads}}+3 \mathrm{H}_{2} \mathrm{O}
\end{gathered}
$$

Figure 11. Proposed mechanism of corrosion and inhibition of aluminum alloy AA6061 before/after PIL addition in diluted sulfuric acid.

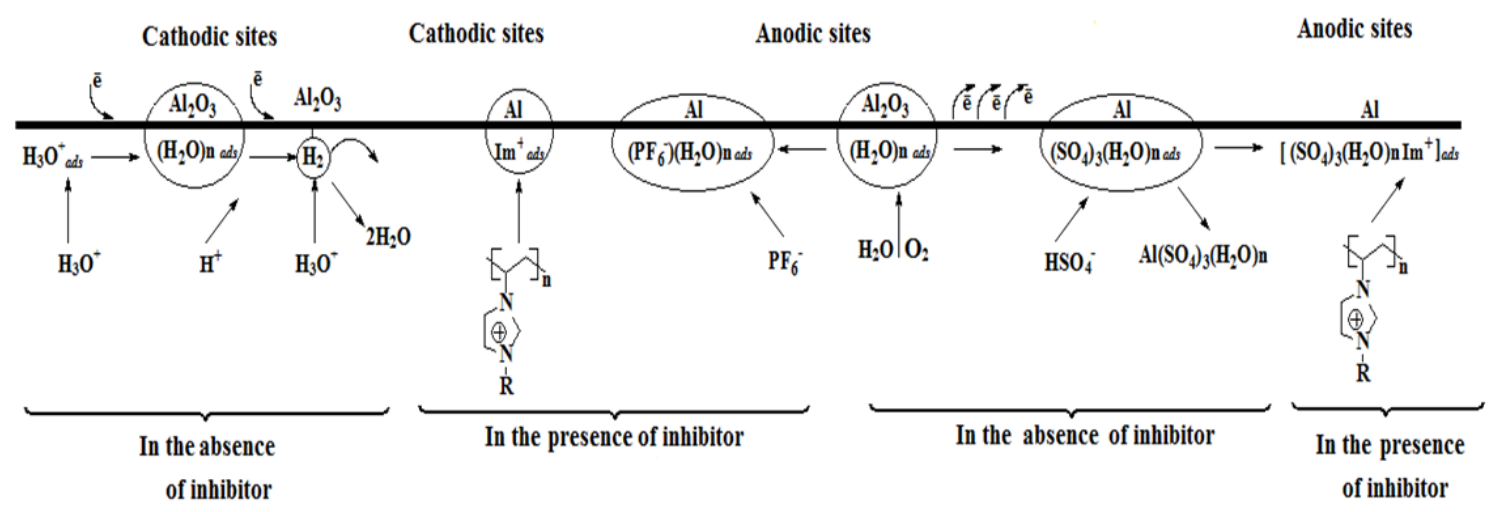

In the presence of PILs, the oxidation reactions are modified; the chemical species $\mathrm{Al}_{2}\left[\left(\mathrm{SO}_{4}\right)_{3}\left(\mathrm{H}_{2} \mathrm{O}\right)_{n}\right]_{\text {ads }}$ can absorb one more bisulfate anion and then interact electrostatically with the cation of each repeating unit $\left(\mathrm{Im}^{+}\right)$of the polymer through the imidazole ring, while the hydrophobic part of the alkylic side chain is preferentially oriented towards the solution, forming a hydrophobic barrier by the formation of $\mathrm{Al}_{2} \mathrm{H}\left[\left(\mathrm{SO}_{4}\right)_{4}{ }^{-}\left(\mathrm{H}_{2} \mathrm{O}\right)_{n} \mathrm{Im}^{+}\right]_{\text {ads }}$ (Equation (10)). At the same time, the ion $\mathrm{PF}_{6}{ }^{-}$ can be adsorbed onto the aluminum alloy AA6061 surface, which led to an excess of negative charge (Equation (11)). The chemical species $\mathrm{Al}\left[\left(\mathrm{H}_{2} \mathrm{O}\right)_{n}\left(\mathrm{PF}_{6}\right)_{4}{ }^{-}\right]$could then electrostatically interact with the $\mathrm{Im}^{+}$(Equation (12)). However, the concentration of $\mathrm{HSO}_{4}{ }^{-}$in solution appeared to be higher than that of $\mathrm{PF}_{6}{ }^{-}$, so that the presence of $\mathrm{Al}_{2} \mathrm{H}\left[\left(\mathrm{SO}_{4}\right)_{4}{ }^{-}\left(\mathrm{H}_{2} \mathrm{O}\right)_{n} \mathrm{Im}^{+}\right]_{\text {ads }}$ is more likely.

$$
\begin{gathered}
\mathrm{Al}_{2}\left[\left(\mathrm{SO}_{4}\right)_{3}\left(\mathrm{H}_{2} \mathrm{O}\right)_{n}\right]_{\text {ads }}+\mathrm{HSO}_{4}^{-}+\mathrm{Im}^{+} \leftrightarrow \mathrm{Al}_{2} \mathrm{H}\left[\left(\mathrm{SO}_{4}\right)_{4}^{-}\left(\mathrm{H}_{2} \mathrm{O}\right)_{n} \mathrm{Im}^{+}\right]_{\text {ads }} \\
\mathrm{Al}_{2} \mathrm{O}_{3}+4 \mathrm{PF}_{6}^{-}+n \mathrm{H}_{3} \mathrm{O}^{+} \leftrightarrow 2 \mathrm{Al}\left[\left(\mathrm{H}_{2} \mathrm{O}\right)_{n}\left(\mathrm{PF}_{6}\right)_{4}^{-}\right]_{\mathrm{ads}} \\
2 \mathrm{Al}\left[\left(\mathrm{H}_{2} \mathrm{O}\right)_{n}\left(\mathrm{PF}_{6}\right)_{4}^{-}\right]_{\text {ads }}+\mathrm{Im}^{+} \leftrightarrow \mathrm{Al}\left[\left(\mathrm{H}_{2} \mathrm{O}\right)_{n}\left(\mathrm{PF}_{6}\right)_{4}^{-} \mathrm{Im}^{+}\right]_{\text {ads }}
\end{gathered}
$$

\subsubsection{Cathodic Reactions}

As the aluminum surface is covered with oxides, which generally have dissimilar dielectric properties, it is more likely that the cathodic reactions occurred both on the metal grain boundaries and on those separating the anodic zones themselves. This way, protons coming from acid dissociation, when approaching the interior of the Helmholtz plane in the cathodic zones, are reduced to release molecular hydrogen and consume the aluminum free electrons (anodic zone) during their oxidation.

$$
\mathrm{Al}_{2} \mathrm{O}_{3}+\mathrm{H}_{3} \mathrm{O}^{+}+\mathrm{e}^{-} \leftrightarrow \mathrm{Al}_{2} \mathrm{O}_{3}\left(\mathrm{H}_{2} \mathrm{O}\right)+\frac{1}{2} \mathrm{H}_{2}
$$


In the presence of CIs, macromolecules competed with protons to occupy active sites on the cathodic zones, which are electrostatically adsorbed through $\mathrm{Im}^{+}$, leading to the adsorption of AlImads (Equation (14)). As the proton size is much smaller than that of $\mathrm{Im}^{+}$, the latter can cover a more extended area; so, the kinetics of the cathodic reaction is slowed and corrosion mitigated.

$$
\mathrm{Al}+\mathrm{Im}^{+}+\mathrm{e}^{-} \leftrightarrow \mathrm{Al} \operatorname{Im}_{\text {ads }}
$$

Some of the properties provided by the protective film on aluminum alloy AA6061 are as follows: (1) The salts of $\mathrm{Al}_{2} \mathrm{H}\left[\left(\mathrm{SO}_{4}\right)_{4}{ }^{-}\left(\mathrm{H}_{2} \mathrm{O}\right)_{n} \mathrm{Im}^{+}\right]_{\text {ads }}$ and $\mathrm{Al}\left[\left(\mathrm{H}_{2} \mathrm{O}\right)_{n}\left(\mathrm{PF}_{6}\right)_{4}{ }^{-} \mathrm{Im}^{+}\right]_{\text {ads }}$ adsorbed on the metallic surface could change its polarity towards the solution, which led to $\mathrm{PF}_{6}{ }^{-}$and//or $\mathrm{HSO}_{4}{ }^{-}$interactions that may induce a multilayer formation on the protective film that functions as a barrier against the aggressive ions in solution; (2) The steric effect of the alkylic side chain located in the imidazole ring through the entire length of the polymeric chain works favorably as hydrophobic areas; additionally, two macromolecules can form a relatively more compact polymeric film owing to opposite charges. This property contributed to the fact that $\mathrm{PImC}_{12}$ was derived as the most efficient of the PILs tested.

As previously described, the inhibition mechanism proposed that PILs in $\mathrm{H}_{2} \mathrm{SO}_{4}$ interacted on both the anodic and cathodic sites formed on the metallic surface. However, results from electrochemical

tests indicated that anodic reactions predominated at the metal solution interface after long time periods; namely, at short times, the PILs affected both the anodic and cathodic reactions, but after $9 \mathrm{~h}$, the kinetics of the oxidation reaction predominated due to the formation of $\mathrm{Al}_{2} \mathrm{H}\left[\left(\mathrm{SO}_{4}\right)_{4}{ }^{-}\left(\mathrm{H}_{2} \mathrm{O}\right)_{n} \mathrm{Im}^{+}\right]_{\text {ads }}$.

\section{Conclusions}

From the study of poly(1-vinyl-3-alkylimidazolium hexafluorophosphate)s as corrosion inhibitors to protect aluminum alloy AA6061 in aqueous sulfuric acid, the following conclusion were derived:

(1) PILs displayed low efficiencies as corrosion inhibitors against uniform corrosion; apparently, this was derived from the highly active competition of aggressive sulfate species and inhibitor molecules to occupy the metallic surface area. ICP-OES indicated a decrease of dissolved $\mathrm{Al}^{3+}$ in solution after PILs, which confirmed their inhibitive action.

(2) PILs inhibitors contributed in decreasing density, morphology and depth of pitting corrosion, though not in a complete scheme, as aluminum alloy AA6061 developed pit regions in aqueous sulfuric acid after relatively long immersion times and low concentrations of PILs.

(3) Inhibitor efficiency improved with the increase in PILs concentration and the decrease in acid concentration in solution. The efficiency of these compounds as corrosion inhibitors displayed the following order: $\mathrm{PImC}_{12}>\mathrm{PImC}_{8}>\mathrm{PImC}_{4}$; in any case, $I_{\mathrm{E}}$ was shown to be time dependent.

(4) PILs adsorption on aluminum alloy in the acidic media follows Langmuir's isotherm; $K_{\text {ads }}$ values indicated that $\mathrm{PImC}_{12}$ is adsorbed more easily on surface than the other PILs of shorter alkylic side chains and lower molecular weights, whereas $\Delta G_{\text {ads }}^{0}$ values suggested that physisorption is the process in control for inhibition.

(5) The synthesized PILs displayed a short protection range for the alloy AA6061. Thus, these PILs are not suitable to be applied in acidic media, as they are not easily adsorbed due to ionic competition, which promotes the formation of a non-uniform CI film on the aluminum alloy surface. 


\section{Acknowledgments}

The authors gratefully acknowledge Conacyt-Mexico for the sponsorship provided. Octavio Olivares-Xometl thanks SNI, BUAP-VIEP and project Conacyt 167232. Paulina Arellanes-Lozada would like to thank the ESIQIE-IPN for the support provided.

\section{Author Contributions}

Paulina Arellanes-Lozada, Octavio Olivares-Xometl, Marco A. Domínguez-Aguilar and Elsa Arce-Estrada carried out electrochemical testing, surface testing, IOCP, analysis of results and discussion. Diego Guzmán-Lucero, Natalya V. Likhanova and Irina V. Lijanova were responsible of the chemical synthesis of compounds, chemical characterization by experimental techniques (FTIR, NMR) and proposed the mechanism of inhibition

\section{Conflicts of Interest}

The authors declare no conflict of interest.

\section{References}

1. Yang, C.C. Electrodeposition of aluminum in molten $\mathrm{AlCl}_{3}-n$-butylpyridinium chloride electrolyte. Mat. Chem. Phys. 1994, 37, 355-361.

2. Fellner, P.; Chrenková-Paučírová, M.; Matiašovský, K. Electrolytic aluminium plating in molten salt mixtures based on $\mathrm{AlCl}_{3} \mathrm{I}$ : Influence of the addition of tetramethylammonium chloride. Surf. Technol. 1981, 14, 101-108.

3. Vargel, C. Corrosion of Aluminium, 1st ed.; Elsevier: San Diego, CA, USA, 2004.

4. Davis, J.R. Corrosion of Aluminium and Aluminium Alloys, 1st ed.; ASM International: Materials Park, OH, USA, 1999.

5. Umoren, S.A.; Ogbobe, O.; Igwe, I.O.; Ebenso, E.E. Inhibition of mild steel corrosion in acidic medium using synthetic and naturally occurring polymers and synergistic halide additives. Corros. Sci. 2008, 50, 1998-2006.

6. Musa, A.Y.; Kadhum, A.H.; Mohamad, A.B.; Takrif, M.S.; Chee, E.P. Inhibition of aluminum corrosion by phthalazinone and synergistic effect of halide ion in $1.0 \mathrm{M} \mathrm{HCl}$. Curr. Appl. Phys. 2012, 12, 325-330.

7. Pourbaix, M. Atlas of Electrochemical Equilibria in Aqueous Solutions, 2nd ed.; NACE: Houston, TX, USA, 1974.

8. Muniandy, M.T.; Rahim, A.A.; Osman, H.; Shah, A.M.; Yahya, S.; Raja, P.B. Investigation of some schiff bases as corrosion inhibitors for aluminium alloy in $0.5 \mathrm{M}$ hydrochloric acid solutions. Surf. Rev. Lett. 2011, 18, 127-133.

9. Nisancioglu, K. Corrosion of aluminium alloys. In Proceedings of the ICCA3, Trondheim, Norway, 22-26 June 1992.

10. Bregman, J.I. Corrosion Inhibitors; Collier-MacMillan Co.: London, UK, 1963.

11. Sastri, V.S. Corrosion Inhibitors: Principles and Application; John Wiley \& Sons: New York, NY, USA, 1998. 
12. Mourya, P.; Banerjee, S.; Singh, M.M. Corrosion inhibition of mild steel in acidic solution by Tagetes erecta (Marigold flower) extract as a green inhibitor. Corros. Sci. 2014, 85, 352-363.

13. Flores, E.A.; Olivares, O.; Likhanova, N.V.; Dominguez-Aguilar, M.A.; Nava, N.; Guzmán-Lucero, D.; Corrales, M. Sodium phthalamates as corrosion inhibitors for carbon steel in aqueous hydrochloric acid solution. Corros. Sci. 2012, 53, 3899-3913.

14. Muralidharan, S.M.; Iyer, S.V. Influence of N-heterocyclics on corrosion inhibition and hydrogen permeation through mild steel in acidic solutions. Anti Corros. Meth. Mater. 1997, 44, 100-109.

15. Khaled, K.F.; Al-Qahtani, M.M.J. The inhibitive effect of some tetrazole derivatives towards Al corrosion in acid solution: Chemical, electrochemical and theoretical studies. Mater. Chem. Phys. 2009, 113, 150-158.

16. Lagrenée, M.; Mernari, B.; Bouanis, M.; Traisnel, M.; Bentiss, F. Study of the mechanism and inhibiting efficiency of 3,5-bis(4-methylthiophenyl)-4H-1,2,4-triazole on mild steel corrosion in acidic media. Corros. Sci. 2002, 44, 573-588.

17. Fouda, A.S.; El-Sherbiny, M.F.; Motawea, M.M. Corrosion inhibition of aluminum alloy in $\mathrm{H}_{3} \mathrm{PO}_{4}$ solution using para-thiazolidinone derivatives. Desalination 2011, 30, 207-216.

18. Guzman-Lucero, D.; Olivares-Xometl, O.; Martinez-Palou, R.; Likhanova, N.V.; Dominguez-Aguilar, M.A.; Garibay-Febles, V. Synthesis of selected vinylimidazolium ionic liquids and their effectiveness as corrosion inhibitors for carbon steel in aqueous sulfuric acid. Ind. Eng. Chem. Res. 2011, 50, 7129-7140.

19. Likhanova, N.V.; Olivares-Xometl, O.; Guzmán-Lucero, D.; Dominguez-Agilar, M.A.; Nava, N.; Corrales-Luna, M.; Mendoza, M.C. Corrosion inhibition of carbon steel in acidic environment by imidazolium ionic liquids containing vinyl-hexafluorophosphate as anion. Int. J. Electrochem. Sci. 2011, 6, 4514-4536.

20. McCafferty, E.; Pravdic, V.; Zettlemoyer, A.C. Dielectric behaviour of adsorbed water films on the $\alpha-\mathrm{Fe}_{2} \mathrm{O}_{3}$ surface. Trans. Faraday Soc. 1970, 66, 1720-1731.

21. El-Taib, H.F.; Haruyama, S. Impedance studies of the inhibitive effect of benzotriazole on the corrosion of copper in sodium chloride medium. Corros. Sci. 1980, 20, 887-898.

22. Metikos-Hukovic, M.; Grubac, Z.; Stupnisek-Lisac, E. Organic corrosion inhibitors for aluminum in perchloric acid. Corrosion 1994, 50, 146-151.

23. Sezer, E.; Ustamehmetoglu, B.; Bayir, A.Z.; Coban, K.; Kalkan, A. Corrosion inhibition effect of 4-(2-Diethylamino-Ethylsulfonyl)-Phthalonitrile and 4,5-Bis(Hexylsulfonyl)-Phthalonitrile. Int. J. Electrochem. 2010, 2011, doi:10.4061/2011/235360.

24. Ren, Y.; Luo, Y.; Zhang, K.; Zhu, G.; Tan, X. Lignin terpolymer for corrosion inhibition of mild steel in 10\% hydrochloric acid medium. Corros. Sci. 2008, 50, 3147-3153.

25. Abed, Y.; Arrar, Z.; Aounit, A.; Hammaouti, B.; Kertit, S.; Mansri, A. An electrochemical study of the action of poly(4-vinylpyridinepolyoxyethylene) as inhibitor for iron in sulfuric acid solution. J. Chem. Phys. 1999, 95, 1347-1355.

26. Bereket, G.; Yurt, A.; Turk, H. Inhibition of corrosion of low carbon steel in acidic solution by selected polyelectrolytes and polymers. Anti-Corros. Methods Mater. 2003, 50, 422-535.

27. Kralijie, M.; Mandie, Z.; Duie, L.J. Inhibition of steel corrosion by polyaniline coating. Corros. Sci. 2003, 45, 98-181. 
28. Umoren, S.A.; Ogbobe, O.; Okafor, P.C.; Ebenso, E.E. Polyethylene glycol and polyvinyl alcohol as corrosion inhibitors for aluminium in acidic medium. J. Appl. Polym. Sci. 2007, 105, 3363-3370.

29. Kroschwitz, J.I.; Mark, H.F.; Bikales, N.M.; Overberger, C.G.; Menges, G. Encyclopaedia of Polymer Science and Technology, 2nd ed.; Wiley-Interscience Publication: Chichester, UK, 1964; Volume 1.

30. Gao, B.; Zhang, X.; Sheng, Y. Studies on preparing and corrosion inhibition behaviour of quaternized polyethyleneimine for low carbon steel in sulfuric acid. Mater. Chem. Phys. 2008, $108,375-381$.

31. Amin, M.A.; El-Rehim, S.S.A.; El-Sherbini, E.E.F.; Hazzazi, O.A.; Abbas, M.N. Polyacrylic acid as a corrosion inhibitor for aluminium in weakly alkaline solutions. Part I: Weight loss, polarization, impedance EFM and EDX studies. Corros. Sci. 2009, 51, 658-667.

32. Rajendran, S.; Sridevi, S.P.; Anthony, N.; Amalraj, A.J.; Sundaravadivelu, M. Corrosion behaviour of carbon steel in polyvinyl alcohol. Anti-Corros. Methods Mater. 2005, 52, 102-107.

33. Olivares-Xometl, O.; Likhanova, N.V.; Domínguez-Aguilar, M.A.; Arce, E.; Dorantes, H.; Arellanes-Lozada, P. Synthesis and corrosion inhibition of $\alpha$ amino acid alkylamids for mild steel in acidic environment. Mat. Chem. Phys. 2008, 110, 344-351.

34. Marcilla, R.; Blazquez, J.; Pomposo, J.; Mecerreyes, D. Tuning the solubility of polymerized ionic liquids by simple anion-exchange reactions. J. Polym. Sci. Part A Polym. Chem. 2004, 42, 208-212.

35. Inductively Coupled Plasma-Atomic Emission Spectrometry; EPA 6010C Method, revision 3, 2007. Available online: http://www.epa.gov/osw/hazard/testmethods/sw846/pdfs/6010c.pdf (accessed on 23 July 2014).

36. Baboian, R.; Dean, S.W., Jr.; Hack, H.P.; Hibner, E.L.; Scully, J.R. Corrosion Test and Standards: Application and Interpretation, 2nd ed.; ASTM International Standards Worldwide: West Conshohocken, PA, USA, 2005.

37. Durnie, W.; de Marco, R.; Jefferson, A.; Kinsella, B. Development of structure-activity relationships for oil field corrosion inhibitors. J. Electrochem. Soc. 1999, 146, 1751-1756.

38. Döner, A.; Kardas, G. N-Aminorhodanine as an effective corrosion inhibitor for mild steel in $0.5 \mathrm{M} \mathrm{H}_{2} \mathrm{SO}_{4}$. Corros. Sci. 2011, 53, 4223-4232.

39. El-Etre, A.Y. Inhibition of aluminum corrosion using Opuntia extract. Corros. Sci. 2003, 45, 2485-2495.

40. El-Etre, A.Y. Inhibition of acid corrosion of aluminum using vanillin. Corros. Sci. 2001, 43, 1031-1039.

41. Döner, A.; Solmaz, R.; Ozcan, M.; Kardas, G. Experimental and theoretical studies of Thiazoles as corrosion inhibitors for mild steel in sulphuric acid solution. Corros. Sci. 2011, 53, 2902-2913.

42. Amin, M.A.; Ahmed, M.A.; Arida, H.A.; Kandemirli, F.; Saracoglu, M.; Arslan, T.; Basaran, M.A. Monitoring corrosion and corrosion control of iron in $\mathrm{HCl}$ by non-ionic surfactants of the TRITON-X series_-Part III. Immersion time effects and theoretical studies. Corros. Sci. 2011, 53, 1895-1909.

43. Amin, M.A. A newly synthesized glycine derivative to control uniform and pitting corrosion processes of Al induced by SCN- anions - Chemical, electrochemical and morphological studies. Corros. Sci. 2010, 52, 3243-3257. 
44. Obot, I.B.; Obi-Egbedi, N.O.; Umoren, S.A. Antifungal drugs as corrosion inhibitors for aluminium in $0.1 \mathrm{M} \mathrm{HCl}$. Corros. Sci. 2009, 51, 1868-1875.

45. Abd El Rehim, S.S.; Amin, M.A.; Moussa, S.O.; Ellithy, A.S. The corrosion inhibition of aluminum and its copper alloys in $1.0 \mathrm{M} \mathrm{H}_{2} \mathrm{SO}_{4}$ solution using linear-sodium dodecyl benzene sulfonate as inhibitor. Mater. Chem. Phys. 2008, 112, 898-906.

46. Pierre, R.R. Handbook of Corrosion Engineering; McGraw-Hill: New York, NY, USA, 2000.

47. Ashassi-Sorkhabi, H.; Es'haghi, M. Corrosion inhibition of mild steel in acidic media by [BMIm]Br Ionic liquid. Mat. Chem. Phys. 2009, 114, 267-271.

48. Li, X.; Deng, S.; Fu, H. Inhibition by tetradecylpyridinium bromide of the corrosion of aluminium in hydrochloric acid solution. Corros. Sci. 2011, 53, 1529-1536.

49. Mercier, D.; Herinx, M.; Barthés-Labrousse, M.G. Influence of 1,2-diaminoethane on the mechanism of aluminium corrosion in sulphuric acid solutions. Corros. Sci. 2010, 52, 3405-3412.

50. Boukerche, I.; Djerad, S.; Benmansour, L.; Tifouti, L.; Saleh, K. Degradability of aluminum in acid and alkaline solutions. Corros. Sci. 2014, 78, 343-352.

51. Obot, I.B.; Obi-Egbedi, N.O.; Umoren, S.A. The synergistic inhibitive effect and some quantum chemical parameters of 2,3-diaminonaphthalene and iodide ions on the hydrochloride acid corrosion of aluminum. Corros. Sci. 2009, 51, 276-282.

52. Amin, M.A. Understanding the inhibitory effect of sodium oleate on the corrosion of Al and Al-Cu alloys in $1.0 \mathrm{M} \mathrm{H}_{3} \mathrm{PO}_{4}$ solution-Polarization studies. J. Appl. Electrochem. 2009, 39, 689-696.

(C) 2014 by the authors; licensee MDPI, Basel, Switzerland. This article is an open access article distributed under the terms and conditions of the Creative Commons Attribution license (http://creativecommons.org/licenses/by/3.0/). 